\title{
Biomarkers in Brain Tumors with Focus on Glioblastoma
}





\title{
Biomarkers in Brain Tumors with Focus on Glioblastoma
}

\author{
Małgorzata Lysiak
}

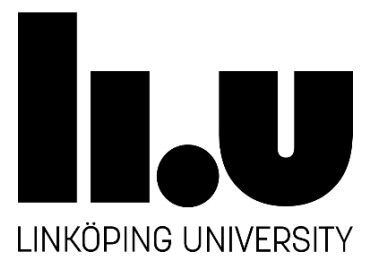

Faculty of Medicine and Health Sciences

Department of Biomedical and Clinical Sciences

Division of Cell Biology 


\section{Main Supervisor:}

Peter Söderkvist, PhD, Professor

Linköping University

\section{Co-supervisors:}

Olle Stål, $\mathrm{PhD}$, Professor

Linköping University

Annika Malmström, $\mathrm{MD}, \mathrm{PhD}$

Linköping University

(C) Małgorzata Łysiak, 2022

ISBN: 978-91-7929-154-9 (Print)

ISBN: 978-91-7929-155-6 (PDF)

ISSN: 0345-0082

Papers I and II have been reprinted with permission of the respective copyright owners.

Paper III is a submitted manuscript, under review.

Paper IV is a manuscript.

Printed by LiU-Tryck, Linköping, Sweden, 2022 
You must demand of yourselves, even if others would not demand of you! John Paul II, 1983

To my family 



\section{Populärvetenskaplig sammanfattning}

I Sverige insjuknar varje år ca 500 patienter med gliom och de flesta drabbas av den mest aggressiva formen, glioblastom (GBM), med en median överlevnad mellan 14-17 månader, även med behandling. Män diagnosticeras upp till $60 \%$ oftare än kvinnor och i vissa studier verkar de ha sämre prognos. De flesta som insjuknar med GBM är äldre och behandlingen utgörs av en kombination av strålning och läkemedlet temozolomid (TMZ) som är ett cytostaikum. Den enda kända biologiska tumörmarkören som kan förutsäga effekt av TMZ behandling är så kallad metylering av DNA i promotorregionen till genen för ett DNA reparationsenzym, $O^{6}$-metylguanin DNA metyltransferas (MGMT). Metylering av MGMT medför en minskad förekomst av enzymet och en försämrad förmåga att reparera DNA skador. Det innebär att DNA skador som orsakas av TMZ inte kan repareras lika effektivt och tumörcellerna dör. Patienter med tumörer som är MGMT metylerade har därför bättre prognos och överlever längre. Det finns ett stort behov av att identifiera ytterligare biomarkörer som kan förklara skillnaderna mellan män och kvinnors sjukdom, men också faktorer av betydelse för effekt av strålbehandling eller för patienter med tumör som inte är MGMT metylerade. Dessa frågor är fokus för denna avhandling. I arbetena I-III undersökte vi könsrelaterade skillnader för GBM, kopplade bla till könskromosomerna Y och X. I arbete IV sökte vi efter så kallade metyleringsspecifika biomarkörer som kan kopplas till exceptionellt lång eller kort överlevnad hos patienter som behandlats med strålning eller TMZ.

Förlust av hela Y kromosomen (loss of chromosome Y, LOY) hos kroppscellerna har associerats till åldrande och har kunnat kopplas till ålderssjukdomar, bl a cancer. Vi undersökte 10 gener på Y kromosomen hos 105 män med GBM och som hade behandlats med TMZ samtidigt med strålning och fann att tumörcellerna ofta saknade hela eller delar av Y-kromosomen, bla kunde förlust av genen "sex determining region Y" (SRY) kopplas till kortare överlevnad. För att konfirmera fyndet analyserades en annan kohort av 219 GBM patienter från "The Cancer Genome Atlas" (TCGA) där lågt genuttryck av SRY användes som indikator på låg aktivitet och eller förlust av $S R Y$ genen och var starkt kopplad till kortare överlevnad.

I arbete II analyserades data från 3 olika kohorter av patient med GBM för att undersöka förekomsten av MGMT metylerad tumör hos män respektive kvinnor. Den ena kohorten bestod av GBM patienter från den Nordiska randomiserade fas 3 studien för patienter 60 år eller äldre, där standard behandling med 60 Gy strålning jämfördes mot strålning till $34 \mathrm{~Gy}$ som ges under kortare tid eller behandling med läkemedlet TMZ. Den andra kohorten var populationsbaserad och alla patienterna erhöll TMZ samtidigt med strålbehandling. Det sista patient materialet kom från TCGA där GBM patienterna erhållit olika typer av onkologisk behandling. I den populationsbaserade kohorten hade kvinnor bättre överlevnad än män och i alla 3 patient kohorterna var det fler kvinnor som hade metylerad $M G M T$ gen än män.

I arbete III undersökte vi androgen receptorn $(A R)$ i GBM tumörvävnad. $A R$ är belägen på Xkromosomen och vi fann att genen förekom i både flera och färre kopior hos tumörcellerna, förändringar som var betydligt vanligare bland kvinnor. Genuttrycket av $A R$ var generellt förhöjd i tumörvävnad utan skillnader mellan könen. Däremot hade förhöjt värde motsatt effekt beroende på kön, där kvinnor uppvisade en kortare överlevnad medan män överlevde längre tid med dessa förändringar. Metyleringsgraden hos $A R$ undersöktes och vilka delar av promotorn skiljde sig mellan män och kvinnor. 
I arbete IV deltog 59 patienter från den Nordiska gliom studien, jämnt fördelade utifrån behandlingsarm och metyleringsstatus på MGMT. Alla patienter hade goda prognostiska faktorer men kort eller lång överlevnad. Vi genomförde helgenoms metyleringsanalys och sökte efter områden i DNA med skillnader i metyleringsgrad hos patienter med kort eller lång överlevnad. Vi identifierade sådana områden i gruppen TMZ behandlade och $M G M T$ metylerade, gruppen 60Gy och MGMT icke-metylerade samt 34Gy och MGMT metylerade. Inga metyleringsskillnader kunde identifieras hos patienter som behandlats med TMZ beroende på om de hade $M G M T$ metylerade tumörceller eller inte. Genom att använda metyleringsprofilen hos tumörcellerna för diagnostik så kunde vi identifiera en felklassificerad tumör som inte var GBM. Slutligen kunde vi också beräkna så kallad “epigenetisk ålder" hos tumören utifrån metyleringsdata. Vi använde 3 olika algoritmer för beräkning. Vi kunde påvisa att i alla olika behandlingsgrupper så hade de med kort överlevnad en trend mot lägre epigenetisk ålder, men fynden var inte signifikanta och kräver verifiering i ett större material.

Sammanfattningsvis så utvidgar denna avhandling vår kunskap kring molekylära olikheter mellan GBM hos män och kvinnor och kopplingen mellan dessa skillnader och överlevnad hos patienterna. Våra resultat talar också för att det kan finnas ytterligare metylerings baserade biomarkörer av betydelse förutom MGMT, såsom tumörens epigenetiska ålder och som kan användas för att skilja mellan patienter med god och dålig prognos.Dom primära hjärntumörerna, gliom, är inte vanliga, men de är obotliga. 


\section{Abstract}

The primary brain tumors, gliomas, are not very common but they are deadly. Each year in Sweden around 500 patients will be diagnosed with a glioma and unfortunately most of them will have the most aggressive type, glioblastoma (GBM). Median survival, even if treated, is poor (14-17 months). Males are diagnosed up to $60 \%$ more often than females and they often have a worse prognosis. GBM affects mainly older patients and treatment includes radiochemotherapy with temozolomide (TMZ). The only known predictive biomarker for TMZ treatment is methylation of the $O^{6}$-methylguanine DNA methyltransferase (MGMT) promoter and patients with methylated $M G M T$ have better outcomes. There is a great need for biomarkers to decipher existing sex differences and others that identify patients that will benefit from radiotherapy (RT) or TMZ despite of unmethylated MGMT.

Papers I-III are focused on investigating sex differences in GBM and in Paper IV we examined the methylation-based biomarkers used in diagnostics, on patients from the Nordic trial with exceptionally good and poor survival when treated with TMZ or RT.

Loss of the Y chromosome (LOY) in male's blood cells is associated with aging and, among other diseases, with cancer. We looked at 10 genes located on chromosome $\mathrm{Y}$ in 105 males with GBM treated with TMZ concomitant with RT and found that they are often deleted. Detected LOY, as well as deletion of the sex determining region $\mathrm{Y}(S R Y)$ gene were associated with shorter overall survival. Low $S R Y$ gene expression analyzed in an additional cohort of 219 samples from The Cancer Genome Atlas (TCGA) was also associated with a shorter survival.

In Paper II we re-analyzed data from three cohorts to compare the frequency of $M G M T$ methylated tumors in males and females and investigated whether sex is an important factor associated with patient's survival. This was done in a GBM cohort from the randomized, phase 3 Nordic trial, which included patients 60 years or older, treated with standard RT (60Gy) vs. hypofractionated RT vs. TMZ given in up to six 4 weekly cycles; in a populationbased cohort, treated with TMZ concomitant with RT and an excerpt of the TCGA cohort of patients treated with different modalities. In all three cohorts there was a higher fraction of $M G M T$ methylated tumors in females and $M G M T$ methylation was predictive of longer survival for those treated with an alkylating agent, such as TMZ.

The third study investigated the androgen receptor $(A R)$, located on chromosome $\mathrm{X}$ as a potential sex susceptibility factor for GBM. We found that the gene encoding for AR can be amplified or deleted in GBM, and these changes are more common in females. The AR gene expression was enhanced in GBM but did not differ between sexes. At the same time, in a separate analysis for males and females, we found that high $A R$ expression is associated with shorter survival in females and longer survival in males Also, the methylation sites in the $A R$ promoter that correlated with gene expression are sex specific.

In Paper IV we included 59 patients from the Nordic trial, equally divided by the treatment arms and MGMT methylation status, with good prognostic factors and with long or short survival. We performed genome-wide methylation analysis and identified differentially methylated sites between those with long and short survival for the TMZ treated, MGMT methylated samples, as well as the 60Gy, MGMT unmethylated and 34Gy MGMT methylated samples. This small pilot study was unable to discern any differentially methylated sites in 
TMZ treated samples with unmethylated MGMT, associated with long or short survival. By using a methylation-based diagnostic classifier, we were able to detect a misclassified sample that was not a GBM. Lastly, we calculated so called 'epigenetic age' of the tumor tissue based on the methylation data and using three different algorithms and found that in all treatment groups short-term survivors tended to have lower epigenetic age, though these results were not significant and need verification in a larger cohort.

In summary, this thesis advances our knowledge on the molecular differences between male and female GBM and the association between these alterations and patients' survival. Our results also suggest that there are potential methylation-based biomarkers apart from the $M G M T$ promoter methylation, that can be used to distinguish between patients with good and poor prognosis, for instance, the epigenetic age. 


\section{Table of contents}

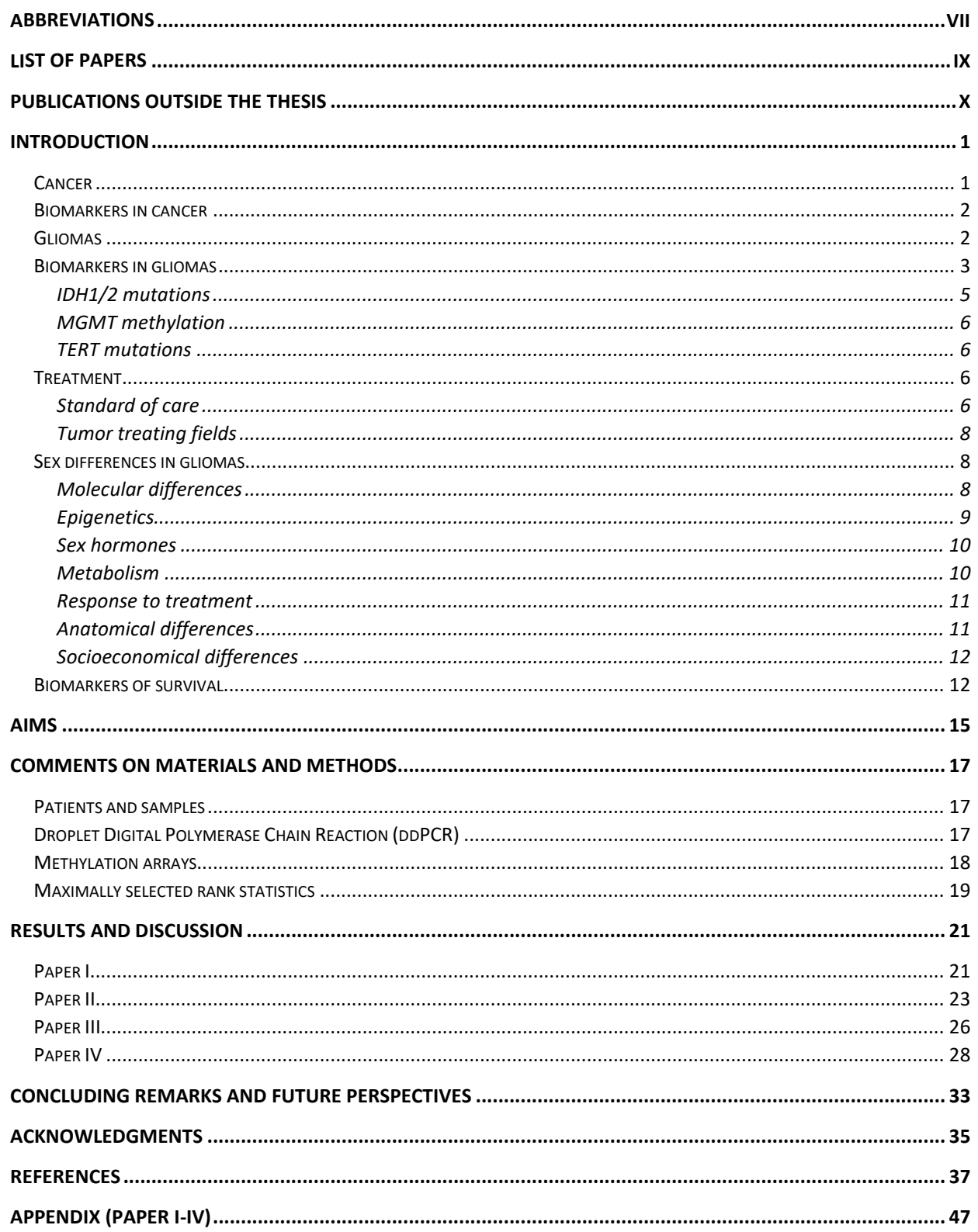




\section{Abbreviations}

$1 \mathrm{p} / 19 \mathrm{q}$ - Short arm of chromosome 1/long arm of chromosome 19

2HG- 2-Hydroxyglutarate

AC- Astrocytoma

AKT- Protein kinase B

AMELY- Amelogenin Y-linked

AR- Androgen receptor

ARSEP1- Arylsulfatase L pseudogene 1

ASCO- American Society of Clinical Oncology

ATRX- Alpha-thalassemia/mental retardation, X-linked

BRD4- Bromodomain containing 4

CBTRUS- Central Brain Tumor Registry of the United States

CDKN2A/B- Cyclin dependent kinase inhibitor 2A/B

cfDNA- Cell-free DNA

CHEK2- Checkpoint kinase 2

CI- Confidence interval

$\mathrm{CN}$ - Copy number

CNS- Central Nervous System

CpG- Cytosine-phosphate-guanine

ddPCR- Droplet digital polymerase chain reaction

Dickkopf2- Dickkopf-related protein 2

DMCs- Differentially methylated CpG sites

DMGs- Differentially methylated genes

EGFR- Epidermal growth factor receptor

EGFRvIII- Epidermal growth factor receptor transcript variant III

EIF1AY- eukaryotic translation initiation factor 1A Y-linked

FFPE- Formalin fixed, paraffin embedded

FGFR- Fibroblast growth factor receptor

GABRA1- Gamma-aminobutyric acid type A receptor subunit alpha 1

GBM- Glioblastoma

G-CIMP- Glioma CpG island methylator phenotype

GLS1- Glutaminase 1

GWAS- Genome wide association study

Gy- Gray, radiation dose

HOXC4- Homeobox C4

HOXD13- Homeobox D13

HOXD8- Homeobox D8

HR- Hazard ratio

ICV- Intracranial volume

IDH1- Isocitrate dehydrogenase 1

IDH2- Isocitrate dehydrogenase 2

JAM-A- Junctional adhesion molecule A

KDM5D- lysine demethylase 5D

LGG- Low grade glioma

LOY- Loss of chromosome Y

MAPK- Mitogen-activated protein kinase 
MDM1/2/4- Mouse double minute 1/2/4

MGMT- O6-Methylguanine DNA methyltransferase

MRI- Magnetic resonance imaging

NEFL- Neurofilament light chain

NF1- Neurofibromatosis type 1

NLGN4Y- neuroligin 4 Y-linked

NR2F2- Nuclear receptor subfamily 2 group F member 2

ODG- Oligodendroglioma

OR- Odds ratio

OS- Overall survival

p16- Cyclin-dependent kinase inhibitor $2 \mathrm{~A}$

p21- Cyclin-dependent kinase inhibitor 1

PD-1- Programmed cell death protein-1

PD-L1- Programmed cell death protein-1 ligand

PIK3CA- Phosphatidylinositol 3-kinase catalytic alpha polypeptide

PTEN- Phosphatase and tensin homolog

RB1- Retinoblastoma 1

RT- Radiotherapy

SLC12A5- Solute carrier family 12 member 5

SRY-Sex determining region $Y$

SVZ- Subventricular zone

SYT1- Synaptotagmin 1

TCGA- The Cancer Genome Atlas

TERT- Telomerase reverse transcriptase

TET- Ten-eleven translocation

TFAP2A- Transcription factor AP-2 alpha

TMSB4Y- thymosin beta 4 Y-linked

TMZ- Temozolomide

TP53- Tumor protein 53

TSS- Transcription start site

TTFs- Tumor treating fields

USPY- ubiquitin specific peptidase 9 Y-linked

UTY-ubiquitously transcribed tetratricopeptide repeat containing, Y-linked

WHO- World Health Organization

WNT- Wingless-related integration site

ZFY- zinc finger protein Y- linked

$\alpha \mathrm{KG}$ - Alpha-ketoglutarate 


\section{List of papers}

I Łysiak M, Smits A, Roodakker KR, Sandberg E, Dimberg A, Mudaisi M, Bratthäll C, Strandeus M, Milos P, Hallbeck M, Söderkvist P, Malmström A. Deletions on Chromosome $\mathrm{Y}$ and Downregulation of the SRY Gene in Tumor Tissue Are Associated with Worse Survival of Glioblastoma Patients. Cancers (Basel). 2021 Mar 31;13(7):1619. doi:

10.3390/cancers 13071619.

II Smits A, Lysiak M, Magnusson A, Rosell J, Söderkvist P, Malmström A. Sex Disparities in MGMT Promoter Methylation and Survival in Glioblastoma: Further Evidence from Clinical Cohorts. J Clin Med. 2021 Feb 3;10(4):556. doi: 10.3390/jcm10040556.

III Lysiak M, Trybuła M, Mudaisi M, Bratthäll C, Strandeus M, Milos P, Hallbeck M, Malmström A. The sex-dependent role of the androgen receptor in glioblastoma- results of molecular analyses. Manuscript, submitted.

IV Lysiak M, Das J, Malmström A, Söderkvist P. Methylome analysis for prediction of long and short-term survival in glioblastoma patients from the Nordic trial. Manuscript 


\section{Publications outside the thesis}

Malmström A, Lysiak M, Åkesson L, Jakobsen I, Mudaisi M, Milos P, Hallbeck M, Fomichov V, Broholm H, Grunnet K, Poulsen HS, Bratthäll C, Strandeus M, Papagiannopoulou A, Stenmark-Askmalm M, Green H, Söderkvist P. ABCB1 singlenucleotide variants and survival in patients with glioblastoma treated with radiotherapy concomitant with temozolomide. Pharmacogenomics J. 2020 Apr;20(2):213-219. doi: 10.1038/s41397-019-0107-z. Epub 2019 Oct 17. PMID: 31624332.

Malmström A, Lysiak M, Kristensen BW, Hovey E, Henriksson R, Söderkvist P. Do we really know who has an $M G M T$ methylated glioma? Results of an international survey regarding use of $M G M T$ analyses for glioma. Neurooncol Pract. 2020 Jan;7(1):68-76. doi: 10.1093/nop/npz039. Epub 2019 Sep 24. PMID: 32025325; PMCID: PMC6993038.

Heenkenda MK, Malmström A, Lysiak M, Mudaisi M, Bratthäll C, Milos P, Strandeus M, Åkesson L, Söderkvist P, Uppugunduri S, Osman A. Assessment of genetic and non-genetic risk factors for venous thromboembolism in glioblastoma - The predictive significance of B blood group. Thromb Res. 2019 Nov;183:136-142. doi: 10.1016/j.thromres.2019.10.009. Epub 2019 Oct 22. PMID: 31677594.

Welander J, Łysiak M, Brauckhoff M, Brunaud L, Söderkvist P, Gimm O. Activating FGFR1 Mutations in Sporadic Pheochromocytomas. World J Surg. 2018 Feb;42(2):482-489. doi: 10.1007/s00268-017-4320-0. PMID: 29159601; PMCID: PMC5762800

Dahlrot RH, Dowsett J, Fosmark S, Malmström A, Henriksson R, Boldt H, de Stricker K, Sørensen MD, Poulsen HS, Łysiak M, Söderkvist P, Rosell J, Hansen S, Kristensen BW. Prognostic value of O-6-methylguanine-DNA methyltransferase (MGMT) protein expression in glioblastoma excluding nontumour cells from the analysis. Neuropathol Appl Neurobiol. 2018 Feb;44(2):172-184. doi: 10.1111/nan.12415. Epub 2017 Jun 28. PMID: 28574607.

Malmström A, Poulsen HS, Grønberg BH, Stragliotto G, Hansen S, Asklund T, Holmlund B, Lysiak M, Dowsett J, Kristensen BW, Söderkvist P, Rosell J, Henriksson R; Nordic Clinical Brain Tumor Study Group (NCBTSG). Postoperative neoadjuvant temozolomide before radiotherapy versus standard radiotherapy in patients 60 years or younger with anaplastic astrocytoma or glioblastoma: a randomized trial. Acta Oncol. 2017 Dec;56(12):1776-1785. doi: 10.1080/0284186X.2017.1332780. Epub 2017 Jul 4. PMID: 28675067.

Roodakker KR, Elsir T, Edqvist PD, Hägerstrand D, Carlson J, Lysiak M, Henriksson R, Pontén F, Rosell J, Söderkvist P, Stupp R, Tchougounova E, Nistér M, Malmström A, Smits A. PROX1 is a novel pathway-specific prognostic biomarker for high-grade astrocytomas; results from independent glioblastoma cohorts stratified by age and IDH mutation status. Oncotarget. 2016 Nov 8;7(45):72431-72442. doi: 10.18632/oncotarget.11957. PMID: 27626492 ; PMCID: PMC5341919.

Mosrati MA, Malmström A, Lysiak M, Krysztofiak A, Hallbeck M, Milos P, Hallbeck AL, Bratthäll C, Strandéus M, Stenmark-Askmalm M, Söderkvist P. TERT promoter mutations and polymorphisms as prognostic factors in primary glioblastoma. Oncotarget. 2015 Jun 30;6(18):16663-73. doi: 10.18632/oncotarget.4389. PMID: 26143636; PMCID: PMC4599297. 


\section{Introduction}

\section{Cancer}

In 2020, more than 19 million people were diagnosed with cancer and 10 million died due to the disease (1). With these numbers, cancer is one of the leading causes of death worldwide and the World Health Organization (WHO) lists efforts for new cancer treatments as essential. In the next 20 years, cancer incidence is expected to rise nearly $50 \%$, which creates enormous challenges for the researchers to find new treatments and health care systems to accommodate the increased number of patients. Cancer is predominantly a disease of older patients, due to the long-term accumulation of risk factors. According to the most recent data from the US based National Cancer Institute's Surveillance, Epidemiology and End Results program the median age of a cancer diagnosis is 66 years (2). There is no doubt that cancer is a disease with a genetic background. The profiles of genetic alterations, e.g., point mutations, amplifications, losses of genetic material or fusions of genes, along with epigenetic modifications of the genome are cancer signatures $(3,4)$. These aberrations often target protooncogenes, which promote cell proliferation but if mutated lead to uncontrolled proliferation of cells. Genetic alterations also target tumor suppressor genes, which have inhibitory effect on the cell cycle, and when mutated, they lose the inhibitory function. However, for the full inactivation, the two-hit hypothesis predicts that both alleles of a tumor suppressor have to be affected but only one allele for a proto-oncogene. Familial syndromes, e.g., Li-Fraumeni syndrome, which are associated with increased risk of cancer, are typically caused by inherited germline mutations in tumor suppressors and a second somatic mutation in the remaining wild-type allele (5). Exposure to ionizing radiation, smoking, alcohol, poor diet, excessive exposure to UV radiation, viral infections are just some of the environmental factors that are known to increase the risk of cancer development due to accumulation of genetic changes (6). However, for many types of tumors risk factors remain unknown.

In females, the most common are cancers of the breast, colorectum, lung, cervix and thyroid, while in males lung, prostate, colorectum, stomach and liver cancers are dominating (data accessed in January 2022) (7). Overall, males are diagnosed with cancer more often than females and have worse prognosis $(7,8)$. Tumors of the brain and central nervous system (CNS) are on the $20^{\text {th }}$ place of the most common cancers, but limited treatment options and the site of the tumor lead to one of the lowest survival rates for such patients. Gliomas are the most common primary malignant brain tumors. The reported annual incidence of gliomas in US is 6 per 100,000 and males are affected more often (9). For glioblastoma (GBM), the most common glioma, male:female ratio is $1.6: 1$ but little is known about the mechanisms causing this difference $(9,10)$.

Cancer treatment usually involves combinations of several modalities and surgery, chemotherapy and radiotherapy (RT) are the most common. Maximal safe resection is the goal when it comes to surgery for gliomas but tumor localization and the proximity to important brain structures might prevent radical removal $(11,12)$. For a successful treatment of any glioma, the chemotherapeutic agent needs to pass the blood-brain barrier to be able to reach the tumor. This greatly limits the number of chemotherapeutics that can be used, even if the blood-brain barrier becomes leaky during the course of the disease. RT is used alone or in combination with chemotherapy for glioma patients but while contributing to the local control of the disease, it also carries risks of adverse events $(13,14)$. Unfortunately, even with these 
treatments, prognosis for glioma patients remains poor $(13,14)$. By studying genetic and epigenetic alterations, we can advance our knowledge about glioma development, including the higher prevalence in males, as well as find new treatment targets and improve identifying which patients would benefit from these treatments. Therapies targeting recurrently mutated genes have been successfully used in a variety of cancers, e.g., lung or colorectal cancer (15). Tyrosine kinase receptors, e.g., epidermal growth factor receptor $(E G F R)$, are often mutated in GBM (16). Unfortunately, until now, clinical trials of tyrosine kinase inhibitors and monoclonal antibodies targeting the receptors have failed to show survival benefit for GBM patients in comparison to standard therapies (13). There is also a growing interest in immune therapies for gliomas, especially immune checkpoint inhibitors, effective, e.g., in melanoma and non-small cell lung cancer $(17,18)$. Inhibition of programmed cell death protein 1 (PD-1) or its ligand (PD-L1) leads to inhibition of the negative regulatory pathways of the immune system and the anti-tumor response. GBM, however, is a tumor with a low immunogenic response, and so far, no significant clinical benefit has been demonstrated for immune checkpoint inhibitors $(13,19)$.

The aim of the studies included in this thesis is to contribute to the development of personalized glioma patient care, focusing on biomarkers associated with sex differences, treatments and survival of GBM patients.

\section{Biomarkers in cancer}

The general meaning of a biomarker is biological characteristic that is objectively measured and evaluated as an indicator of normal biological or pathological processes, or a response to a therapeutic intervention. Hence, attempts to find biomarkers for cancer have become a priority for many researchers. Depending on the purpose, diagnostic, prognostic or predictive biomarkers can be distinguished, with the possibility of more than one category being suitable. There are countless examples of what can be used as a biomarker, starting with simple biochemical blood tests, through magnetic resonance imaging (MRI) results to transcriptome profiling of a tumor. In recent years we have seen an immense increase in the understanding of basic molecular mechanisms in tumor formation, as well as development and identification of molecular biomarkers, accelerated by the rapid development of high throughput technologies.

\section{Gliomas}

In Sweden, more than 500 patients are diagnosed yearly with glioma (20). GBM is the most common among gliomas and accounts for nearly half (48.6\%) of the malignant tumors of the CNS (9). The yearly incidence rate for GBM is $3.23 / 100000$ and the peak is in the $6^{\text {th }}$ decade of life. There is also a sex disproportion, with males being diagnosed $60 \%$ more often than females $(9,10)$. GBM patients have the worst prognosis, with a median survival of 14-17 months (21). As expected, comorbidities reduce survival by more than 6 months (22). Low grade gliomas (LGG) are diagnosed in younger patients, with a mean age of 41 years and a median survival of approximately 7 years. Even though prognosis is much better, patients with LGG still suffer a fatal disease (23).

Demographically, older age, being a male of European ancestry (non-Hispanic) and having higher socioeconomic status are associated with increased glioma risk (24). Gliomas are thought to be sporadic cancers, with only up to $5 \%$ having familial component $(25,26)$ and 
only $1-2 \%$ being caused by syndromes with Mendelian inheritance, e.g. Li-Fraumeni syndrome, neurofibromatosis 1 and 2, Turcot syndrome and multiple hamartoma $(24,26)$. According to current reports, there are 25 loci discovered through 8 genome-wide association studies (GWAS) that can explain up to $30 \%$ of glioma incidences (24). Most of these variants can be found in the genes commonly mutated in gliomas.

Exposure to ionizing radiation is the only environmental factor known to increase the risk of gliomas (26). Respiratory allergies, asthma and eczema have been reported to reduce the risk of glioma by $30 \%$ (OR: $0.72,95 \%$ CI: $0.58-0.90)(24,26,27)$. Also, the use of statins to treat hypercholesterolemia and use of non-steroidal anti-inflammatory drugs, in this case aspirin, are both associated with reduced risk of glioma (24). A recent meta-analysis showed no correlation between diet and risk of glioma development (28). Alcohol intake is a known risk factor for many cancers (29) and a study based on data collected from over 200000 individuals showed a surprising reduction in glioma risk related to alcohol consumption, both, in males and in females (30). Smoking, use of cellular phones and low frequency electromagnetic fields have been suggested as risk factors, but conclusive evidence is not available (24).

\section{Biomarkers in gliomas}

Historically, gliomas are a very heterogenous group of tumors, often causing difficulties for pathological diagnosis. Currently, they are relatively well defined at the molecular levels, thanks to the international initiatives, like The Cancer Genome Atlas (TCGA) $(16,31,32)$. Although the exact etiology of gliomas remains unclear, aberrations in important cellsignaling pathways have been described (Figure 1) (16). Deregulation of these pathways leads to the acquisition of the hallmarks of cancer, which among others include uncontrolled proliferation, resisting cell death, inducing angiogenesis, evading immune destruction, deregulation of cell metabolism and capacity to metastasize, the latter being very rare in gliomas (33). For GBM, the most common chromosomal alteration is gain of chromosome 7, where the $E G F R$ gene is often found amplified. In addition to amplifications, EGFR carries point mutations and an alternative transcript, which lacks exons 2-7 (EGFR variant IIIEGFRvIII), is commonly detected. In total, more than half of GBM have alterations in EGFR. Highly recurrent chromosomal loss is found on chromosome 10, with common deletions and mutations of a tumor suppressor, phosphatase and tensin homolog (PTEN). About $10 \%$ of tumors have mutations in the neurofibromatosis 1 (NF1) tumor suppressor. The tumor protein 53 (p53) pathway is altered in over $80 \%$ of tumors, through deletions or mutations of TP53, amplifications of mouse double minute 1/2/4 homologous proteins (MDM1/2/4) responsible for facilitating p53 degradation and/or deletions of cyclin dependent kinase inhibitor $2 \mathrm{~A} / \mathrm{B}$ $(C D K N 2 A / B)$. The $C D K N 2 A / B$ deletions, in addition to their role in the p53 pathway, are also responsible for deregulation of the retinoblastoma $1(\mathrm{Rb} 1)$ pathway, which is affected in nearly $80 \%$ of the tumors. Apart from $C D K N 2 A / B$ deletions, the pathway is also affected by $R B 1$ mutations or deletions and amplification of cyclin dependent kinases 4/6 (CDK4/6). Aberrations in receptor tyrosine kinases, like $E G F R$, platelet derived growth factor receptor $(P D G F R)$ or fibroblast growth factor receptor $(F G F R)$ are complemented by mutations in the PIK3CA/Akt signaling pathway $(16,31)$.

These molecular alterations are reflected in the gene expression profiles, which through clustering analysis and in combination with gross genetic alterations data are used to distinguish four GBM subtypes (34). The mesenchymal subtype is enriched for NF1 
mutations and $C D K N 2 A$ deletions, whilst loss of chromosome 7, gain of chromosome 10 and EGFR amplifications are the main characteristics of the classical subtype. The proneural subtype collects tumors with PDGFR, TP53 alterations and includes tumors with isocitrate dehydrogenase 1 mutations (IDHI). The neural subtype is classified based on the expression of neuron markers, such as NEFL, GABRA1, SYT1 and SLC12A5.

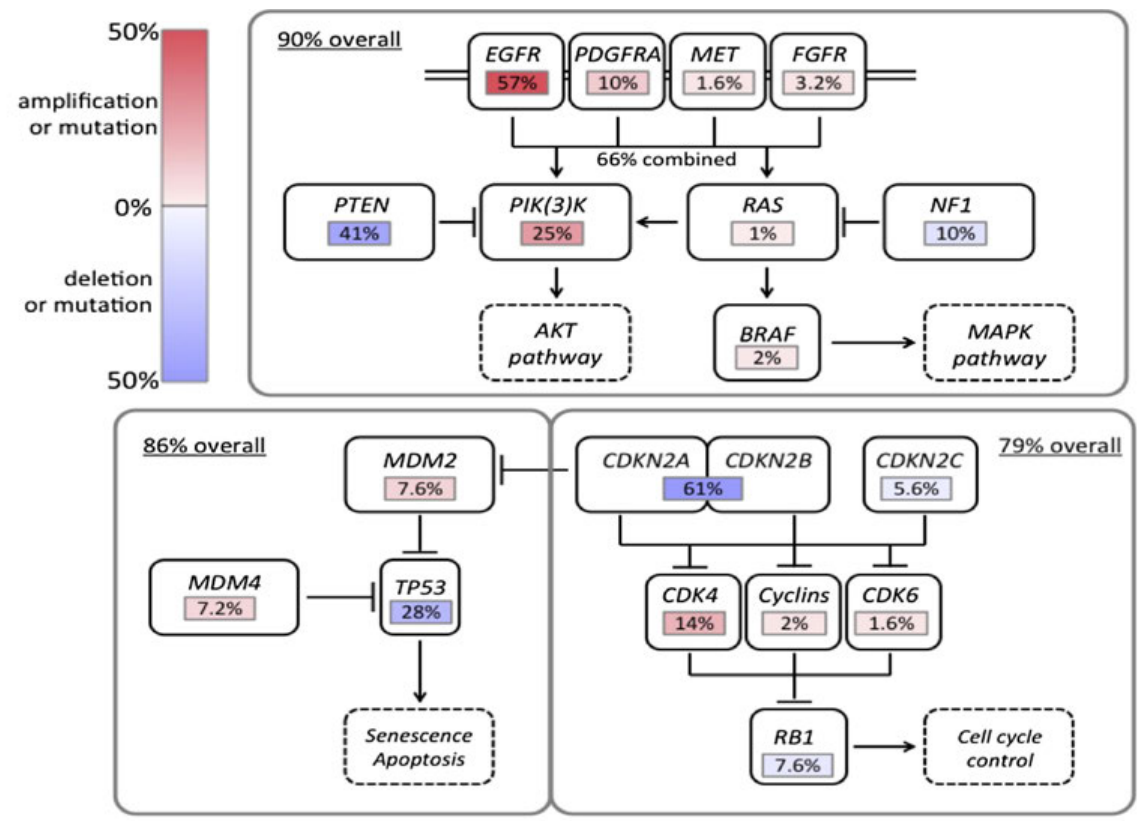

Figure 1. Genes and pathways altered in GBM. Reprinted with permission from (16).

Epigenetic changes together with somatic alterations have impact on tumor development (33). Analysis of DNA methylation and clustering analysis revealed that just as transcriptomes, methylomes can be used for subclassification of GBM (16). A study from TCGA network found that by using data from DNA methylation arrays, GBM tumors can be divided into 6 subtypes, partially overlapping with the subtypes defined by the transcriptomes and correlating with the somatic alterations. This gave the foundation to another classification of CNS tumors, published by Capper et al., who used genome-wide methylation profiling to create a methylation-based CNS tumor classifier and a further subclassification of GBM, IDH wild-type tumors into 8 subclasses (35). Despite high expectations for a universal brain tumor classifier, several studies which used a single-cell or spatial biopsy analysis approach have shown that gliomas still remain heterogeneous when it comes to transcriptome and methylome profiles (36-39).

Comprehensive studies of LGG found that mutations in the $I D H 1 / 2$ genes are very common in these tumors, as well as mutations in TP53, alpha-thalassemia/mental retardation, X-linked $(A T R X)$ and co-deletions of the 1p/19q chromosomal arms (32). Both, $I D H 1 / 2$ mutations and $1 \mathrm{p} / 19 \mathrm{q}$ co-deletion are considered as biomarkers for good prognosis.

Results of these studies finally led to an update of the previous CNS tumor classification, enforced since 2007 (40). The updated classification, which for the first time included molecular biomarkers next to the histological review of the tumor tissue, was introduced by 
WHO in 2016 and has been recently amended $(14,41)$. The current algorithm for classification of diffuse astrocytic and oligodendroglial glioma is depicted in Figure 2. The first-line molecular assessment includes $I D H 1 / 2$ mutations, which separates astrocytomas (AC) and oligodendrogliomas (ODG), both IDH-mutated, from IDH wild-type GBM tumors (from here on referred to as GBM).

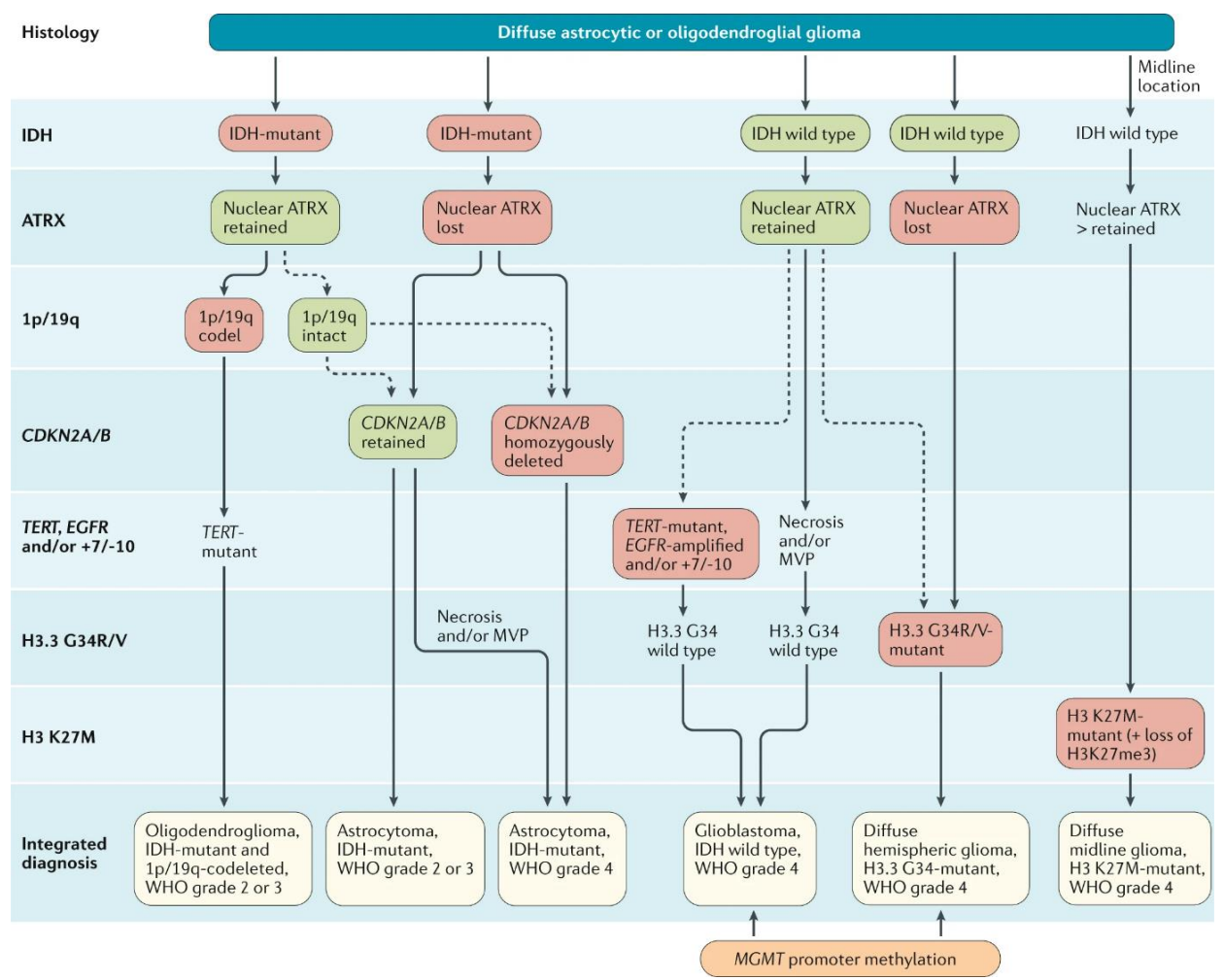

Figure 2. Current diagnostic algorithm for diffuse gliomas with amendments to the classification introduced in 2016. Reprinted with permission from (14). MVP- microvascular proliferation, H3.3G34- histone H3.3 glycine 34, H3K27M- methionine substitution of lysine at residue 27 of histone H3, MGMT- O6-methylguanine-DNA methyltransferase, TERT- telomerase reverse transcriptase, WHO- World Health Organization

\section{IDH1/2 mutations}

The $I D H 1 / 2$ genes are coding for an enzyme, which participates in the tricyclic acid cycle. IDH1 is located in the cytosol and peroxisomes, while IDH2 is found in the mitochondrial matrix. They are responsible for catalyzing the oxidative decarboxylation of isocitrate to $\alpha$ ketoglutarate $(\alpha-\mathrm{KG})$. In gliomas, missense mutations most commonly affect codon 132 of $I D H 1$ and codon 172 of $I D H 2$, and these mutations are mutually exclusive. These two variants alter the IDH enzymatic activity resulting in the formation of D-2-hydroxyglutarate ( $2 \mathrm{HG}$ ) instead of $\alpha-\mathrm{KG}$. Accumulation of $2 \mathrm{HG}$ inhibits the activity of multiple dioxygenases, histone demethylases, and the ten-eleven translocation (TET) family of 5-methylcytosine hydroxylases. TET enzymes participate in the DNA demethylation process and inhibition leads to accumulation of methylation of $\mathrm{CpG}$ sites throughout the genome (42). This, together 
with inhibition of histone demethylases, introduces epigenetic changes that are specific to IDH-mutated tumors. In fact, IDH mutations are associated with a glioma cytosine-phosphateguanine $(\mathrm{CpG})$ island methylator phenotype (G-CIMP) and these tumors have a better prognosis (43).

\section{MGMT methylation}

DNA methylation in gliomas is important for one more reason and it mainly concerns GBM tumors. For patients treated with an alkylating agent temozolomide (TMZ), methylation in the promoter region of the $O^{6}$-methylguanine-DNA methyltransferase (MGMT) gene is associated with an improved overall survival (OS) and is used as a predictive biomarker $(13,14,44,45)$. MGMT participates in DNA repair by removing alkyl groups from the $\mathrm{O}^{6}$ position of guanine. Methylation of the promoter region regulates gene transcription and availability of the protein. The increased methylation leads to decreased levels of the protein this resulting in a less effective DNA repair, reinforcing the cytotoxic and apoptotic effect of the treatment with an alkylating agent (44). Current guidelines for treatment of gliomas highlight the importance of MGMT promoter methylation as a biomarker for informed treatment selection $(13,14)$.

\section{TERT mutations}

Mutations in the promoter of telomerase reverse transcriptase (TERT) are the most common mutations found in GBM, in up to $86 \%(46,47)$. Two mutually exclusive hotspots are located -124bp and -146bp upstream of the transcription start site (TSS) and both are C>T transitions, which create DNA consensus sites enabling binding of transcription factors and increased expression of the gene $(46,48)$. TERT promoter mutations as well as TP53, EGFR, and PTEN mutations are believed to occur early during gliomagenesis because they were found in matched GBM tissue samples and the distant subventricular zone (SVZ), which is believed to be the place of origin of gliomas (49). TERT promoter mutations have been associated with shorter OS (46), although results presented at the European Association of Neuro-Oncology Meeting 2021 revealed no correlation between TERT mutations and clinical outcomes (OS, progression free survival) (47), questioning the prognostic nature of this biomarker. Due to their prevalence in GBM, mutations in TERT promoter can be used as a tumor marker in cellfree DNA (cfDNA) in liquid biopsies and a detection method with a sensitivity of over $60 \%$ has been recently described (50). TERT mutations, next to EGFR and IDH mutations are markers for sporadic gliomas, as in tumors caused by exposure to ionizing radiation, these mutations do not occur (51).

\section{Treatment}

\section{Standard of care}

After positive diagnostic MRI, for all gliomas, maximal safe resection is preferred $(11,12$, 14). If this approach is not possible due to the risks it carries, a biopsy should be performed instead, with very few exceptions (14). This will allow for a diagnosis and choice of the therapy.

For GBM, concomitant radiochemotherapy with temozolomide is considered a standard treatment regimen (52). It consists of TMZ administered daily $\left(75 \mathrm{mg} / \mathrm{m}^{2}\right)$ for 6 weeks together with RT in fractions of $2 \mathrm{~Gy}$ per day weekdays for 6 weeks to a total of $60 \mathrm{~Gy}$. This is followed by up to 6 cycles of TMZ given in $150-200 \mathrm{mg} / \mathrm{m}^{2}$ days $1-5$ in each cycle (52). The 
only predictive biomarker for TMZ treatment is methylation of the MGMT promoter $(44,45)$ but TMZ is used also for patients with unmethylated MGMT in this setting (Figure 3) (14).

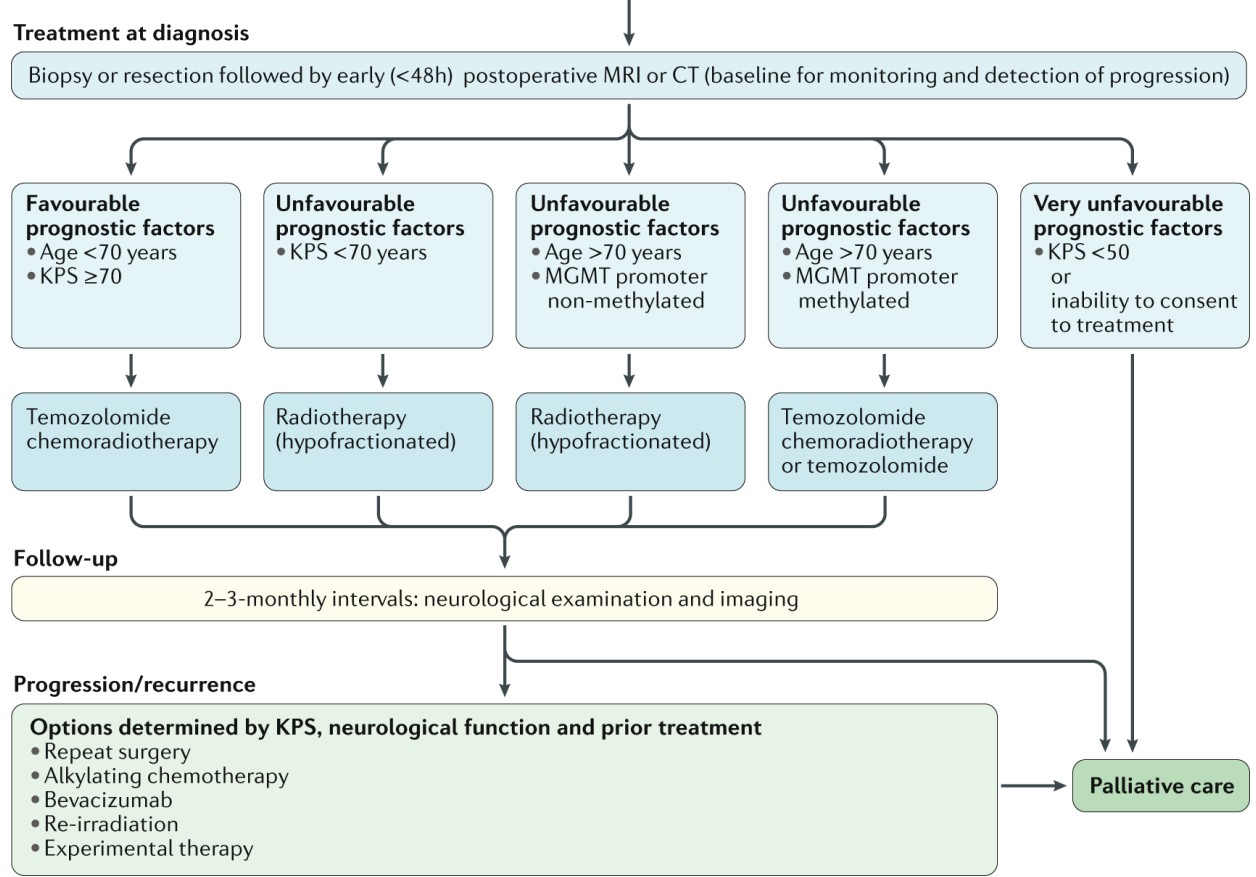

Figure 3. Algorithm for treatment selection for GBM IDH wild-type patients. In each case, an appropriate clinical trial can be considered instead of the treatment recommended by the algorithm. Addition of tumor treating fields for patients who have received radiotherapy concurrent with temozolomide can also be considered (53). Reprinted with permission from (14). KPS- Karnofsky performance status

Deviations from concomitant radiochemotherapy with temozolomide are dictated by the presence of unmethylated $M G M T$ and poor performance status. Hypofractionated RT is a treatment offered especially to elderly patients with unmethylated $M G M T$, who are unfit for combination therapy. Cases with methylated MGMT are offered TMZ only. For patients over 65-70 years with a good performance status hypofractionated radiochemotherapy with TMZ can be considered. There are currently no predictive biomarkers for RT (14).

Current recommendations encourage enrollment of patients into clinical trials to accelerate finding of new treatments (14). This entails biomarker analysis upon enrollment (as entry requirements), which is especially important for targeted treatments, as well as post-hoc subgroup analyzes of biomarkers.

Treatment at progression/recurrence is dictated by the treatment, which the patient has received for the newly diagnosed tumor, performance status and neurological function. The use of humanized vascular endothelial growth factor antibody, bevacizumab, has been shown 
to extend progression free survival and help to decrease peritumoral edema but does not influence the overall survival, therefore it is not approved in all countries for treatment of the recurrent GBM (13).

\section{Tumor treating fields}

At first, tumor treating fields (TTFs) were received quite skeptically by the neuro-oncology community, but this modality has since been proven to significantly extend life of GBM patients. It is a non-invasive treatment modality that acts through low-intensity $(1-3 \mathrm{~V} / \mathrm{cm})$, intermediate-frequency $(100-300 \mathrm{kHz})$, alternating electric fields which are delivered via cutaneous transducer arrays worn by the patient for the majority of the day. The alternating electric fields exert force on dipole molecules, which interferes with, e.g., microtubule polymerization during mitosis leading to reduced proliferation (54). Sweden is one of a few countries offering TTFs to patients. Importantly, TTFs were shown to extend survival of GBM patients by 5 months when added to concomitant radiochemotherapy with TMZ in the primary setting $(53,54)$.

\section{Sex differences in gliomas}

Male dominance in cancer is present throughout many malignancies $(8,55)$. Among primary CNS tumors, all gliomas are more frequently diagnosed in males than females, whereas meningiomas are more common in females (9). GBM is diagnosed $60 \%$ more often in males (10). Some studies have suggested survival advantage of females, but recent reports do not support these claims $(10,56,57)$.
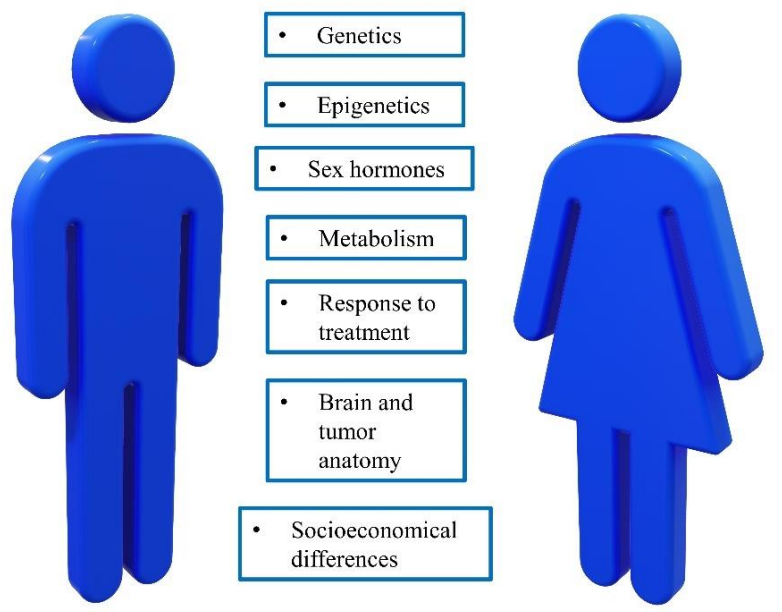

Figure 4. Factors underlying sex differences in gliomas, which are discussed in detail in the section Sex differences in gliomas.

\section{Molecular differences}

Many genetic variants are associated with glioma risk, and several studies report on sexspecific variants as well. A GWAS from 2018 showed that rs11979158 carries a risk only for males and rs55705857 is more strongly associated in females (58). A study published recently 
revealed that female-specific association can be found for some TERT variants and malespecific associations are found for certain $E G F R$ variants (59).

There is a larger sex disparity in mesenchymal and neural subtypes of GBM than in classical and proneural (60). A mesenchymal GBM model (NF1-/dominant negative p53 mice) derived from males is reported to exhibit, after EGF treatment, a higher stem-like behavior and proliferation rate in comparison to the model based on female cells. The study disclosed that these effects were mediated by the sex differences in the inactivating phosphorylation of the $\mathrm{Rb}$ protein, which was greater in male mice (60). Another study found that the sex differences of $\mathrm{Rb}$ regulation are dependent on the $\mathrm{p} 21$ and p16 activity in astrocytes (61). Both, p21 and p16 are cyclin dependent kinase inhibitors (62). Once cyclin dependent kinase inhibitors are activated, they prevent $\mathrm{Rb}$ phosphorylation and inhibit cell cycle progression (62). In a GBM mouse model, in response to DNA damage, female astrocytes had a higher activity of p21 and p16 leading to cell cycle arrest, whereas male astrocytes continued to proliferate (61). The TP53 gene, named the guardian of our genome, is mutated in more than half of GBM (34). Haupt et al. showed that the p53 pathway is associated with male dominance in various types of cancer, which included a higher frequency of TP53 mutations, higher frequency of mutations of $\mathrm{p} 53$ negative regulators located on the $\mathrm{X}$ chromosome, both in males, and lower expression of the $\mathrm{X}$ chromosome mutated alleles in females (63). The importance of p53 has also been emphasized in a recent study by Rockwell et al., who reported that 6 codons of TP53 carry mutations at a sex-specific frequency; 4 codons more frequently mutated in females and 2 in males (64). This further led to the activation of different transcription programs depending on the sex of the mouse astrocytes (64).

Another described example of a difference with a molecular background is the association between high expression of Frizzled-7, a Wnt receptor, and poor survival of only male GBM patients, despite the presence of high Frizzled-7 expression in female tumors as well (65).

Zhang et al. reported that female gliomas (GBM and LGG) have higher mutation burden than male tumors, which can partially be attributed to the high mutation frequency of the $\mathrm{X}$ chromosome (66). This TCGA-based study also showed that the mitogen-activated protein kinase (MAPK) pathway is characterized by clonal mutations in female GBM, and that receptor tyrosine kinases are more likely to have clonal mutations in male LGG (66). Another TCGA-based analysis revealed transcriptomic sex differences, with integrin signaling being the most specific for females and cell cycle regulation pathway being male specific (67).

In addition to the intrinsic molecular differences between the sexes in GBM, there are also differences that occur in the tumor microenvironment. Microglia, one of the components of the tumor microenvironment, interacts with tumor cells through the junctional adhesion molecule A (JAM-A), which helps to maintain the GBM cancer stem cells (68). Interestingly, this may be true only in the male tumors, as JAM-A deficiency in female mice injected with GBM cells induced pro-tumorigenic microglia behavior (69).

\section{Epigenetics}

The embryonic development of the brain, as any other tissue, requires epigenetic changes (70, 71). DNA methylation is the most widely studied component of epigenetics. Importantly, the acquired epigenetic marks can differ between sexes (72) and be dictated by sex hormones, e.g. it has been shown that treatment with testosterone-propionate of mouse embryonic neural 
stem cells leads to a global decrease of DNA methylation in both, XX and XY cells (73). In the developing mammalian brain, researchers found a decreased activity of DNA methyltransferases in males compared to females, contributing to the sex differences in methylation (74). As neural stem cells of the SVZ are thought to be involved in the gliomagenesis (49), one should expect epigenetic sex differences in the tumors as well. In fact, a recent study based on TCGA data showed that methylation of CpG sites differs between sexes in all glioma tumors (75). In all female gliomas, hypermethylated differentially methylated $\mathrm{CpG}$ sites (DMCs) were found in the $\mathrm{CpG}$ island regions, associated with gene promoters. In contrast, in males, the hypermethylated DMCs were primarily localized in the so-called open sea regions. The same study proposed that in male GBM, hypermethylation affects proapoptotic genes, leading to their down-regulation and in females, hypermethylation provides protective effect by down-regulating cell migration genes (75).

A few studies suggested that $M G M T$ promoter methylation, described above, was associated with longer survival, but only in females, and that the fraction of patients with methylated $M G M T$ is significantly higher among female patients $(65,76)$. We explored this subject further in Paper II of this thesis.

Silencing of one of the $\mathrm{X}$ chromosomes is possible thanks to the long non-coding RNA Xist (77). About $15 \%$ of the genes escape the inactivation (78) and recent reports show that a portion of the escaping genes can act as tumor suppressors or oncogenes $(79,80)$, thus likely contributing to sex disparity in cancer. One of the studies showed that a skewed inactivation of the $\mathrm{X}$ chromosome measured in the location of the androgen receptor $(A R)$, leads to increased risk for developing high-grade glioma in young females (<40 years) (81).

The bromodomain containing 4 (BRD4) gene codes for a protein that binds to the acetylated histones and aids accumulation of enhancers to drive transcriptions of genes (82). As an epigenetic regulator, Brd4 was found to bind different enhancers in male and female astrocytes of the GBM mouse model; oncogenes and stem cell markers in males and tumor suppressors in females (82). This translated into increased proliferation in Brd4 knock-down in females and decreased proliferation in males.

\section{Sex hormones}

It can be argued that the hormonal influence on glioma development is subtle, if any. There is no sudden increase in the incidence of gliomas during and after puberty (83) and data on the increased risk of glioma due to exposure to exogenous hormones are inconclusive, although they tend to lean towards protective properties of estrogens (84). However, in vitro and in vivo studies indicate that by affecting signaling pathways of sex hormones, we may be able to modulate response to radio- and chemotherapy $(85,86)$. Zhou et al. showed that GBM cells overexpressing estrogen receptor $\beta$ were sensitized to TMZ treatment (85), and Werner et al. reported that inhibition of the AR sensitizes GBM cells to radiotherapy (86). With the current knowledge, sex hormones are not considered as a causative factor behind the sex disparity in gliomas, but they do not seem to be neutral to the disease either.

\section{Metabolism}

One of the hallmarks of cancer cells is increased glucose metabolism via anaerobic glycolysis, despite conditions appropriate for oxidative phosphorylation (87). A difference in metabolic activity of males and females can be seen already early in life, during embryogenesis (88). 
Ippolito et al. hypothesized that metabolic sex differences may even exist in glioma (89). In a study, based largely on TCGA collection of LGG, they found that increased expression of a set of 11 genes involved in the glycolytic pathway, defined as high-glycolytic group, correlated with short OS. However, this was only observed in males, as no such correlation was found in females, even though the levels of transcripts were similar in both sexes.

In a very recent report, the same group analyzed the glutamine metabolism and showed that glutamine uptake is higher in male GBM (90). Additionally, the glutaminase 1 (GLS1) enzyme, which metabolizes glutamine to glutamate, was upregulated in male specimens and in the in vitro experiments only male cells exhibited sensitivity to GLS1 inhibition. Using a dataset of 757 metabolites analyzed in 76 GBM patients, Sponagel, et al. also noted a general male bias towards amino acid and carbohydrate metabolism and a female bias towards lipid metabolism (90), which is consistent with observations made in adult healthy individuals (91). This suggests that future treatment approaches targeting tumor metabolism should also consider the sex of the patients, e.g., antiglycolytic agents or GLS1 inhibitors could be more suitable for male patients.

\section{Response to treatment}

One of the adverse effects related to TMZ treatment is myelosuppression and females are at higher risk of severe myelotoxicity (92), which might be caused by the differences in drug metabolism. This is also consistent with the general observations about adverse effects of cancer treatments in females (93). However, females seem to respond better to the standard of care treatment regimen (surgery, focal RT and TMZ), as shown by Yang et al. (67).

Significant reduction in GBM growth rate was found there only in females, following TMZ treatment, despite an equal sex distribution of initial tumor growth velocities. This having a direct impact on OS differences. Unfortunately, this study did not account for the effect of $M G M T$ promoter methylation status in the analysis.

The use of immunotherapy as cancer treatment offers many new possibilities, but its use in GBM is still limited due to unsatisfying efficacy (94). It has been suggested that sex differences in the immune system may translate into different efficacy of immunotherapy (95), e.g., studies in other cancers suggest that immune checkpoint inhibitors could bring more benefits to males $(95,96)$, but it is yet to be properly evaluated for GBM patients.

\section{Anatomical differences}

A Norwegian group hypothesized that higher incidence of glioma is associated with a larger size of the brain, which is the effect of the higher number of stem cell divisions (97). On average, male brains are larger than female brains and in this study brain size was expressed as the intracranial volume (ICV) assessed through the MRI scans. Not only glioma patients had larger ICV than the control group, but also, male patients had larger ICV than females. The study also reported that for any person, an increase in the ICV by $100 \mathrm{ml}$ resulted in the increase of odds ratio for a high-grade glioma diagnosis by 1.7-fold (95\% CI: 1.44-1.98, $P$ < 0.001) (97). Height is thought to correlate with the brain size and a study conducted in Israel showed that increased adolescent height is a risk factor for glioma development in males but not for females (98). Billelo et al. reported that GBM is located more frequently in the right temporal lobe in females and the left side is more common in males (99). Also, female tumors were significantly larger than male tumors $\left(15.021 \mathrm{~cm}^{3}\right.$ vs. $\left.11.701 \mathrm{~cm}^{3}, \mathrm{p}=0.005\right)$. Another 
study found a sex difference in the frontal and temporal location of GBM, with males more likely to have tumors in the frontal lobe and females more likely to be affected in the temporal lobe (100). Additionally, combined analysis for both sexes showed that tumors in the frontal lobe correlated with better overall survival in comparison to those located in the temporal lobe.

\section{Socioeconomical differences}

This thesis is based on three papers (I-III) that deal with the molecular aspects of sex differences in GBM, but the socio-economic determinants related to the patient's sex cannot be overlooked, as they may affect diagnosis, treatment and survival. Socioeconomic differences are present even in countries with universal healthcare systems (101). In Sweden, there is a unique opportunity to study diseases in such a broad spectrum thanks to the comprehensive registers. Data published in 2016 from a Swedish population-based registry of Stockholm-Gotland region for primary intracranial tumors showed that male patients had more inpatient days (overnight stays at the hospital) one year after diagnosis (27.2 days; CI 95\%: 24.4-29.9) in comparison to females (21.8 days; CI 95\%: 19.7-23.9) (22). For the outpatient visits (any consultancy without overnight stay) one year after diagnosis, the difference was even more striking, with 51.6 days (CI 95\%: 47.8-55.3) for male patients and 35.6 days (CI 95\%: 33.1-38.2) for female patients, even though there was no difference between sexes for the in- and outpatient days one year before the diagnosis. It should be noted, however, that the analysis did not separate the sexes in high- and low-grade tumors, and males are more often diagnosed with high grade gliomas. Interestingly, the same study showed no differences between sexes in the lead time from diagnosis (understood here as a first radiologic suspicion of the malignancy) to surgery, surgery to histopathological report and surgery to start of non-surgical treatment (chemo- and radiotherapy). A later study based on the Swedish registry, which included only LGG, also showed no sex differences regarding waiting time, surgical procedure or number of surgery-related complications that would lead to re-operation, despite worse preoperative performance status of females and higher fraction of asymptomatic male patients (102). Different models of healthcare systems undeniably influence access to treatments. In a recent study based on the Central Brain Tumor Registry of the United States (CBTRUS), analysis of more than 170000 patients revealed that males more often received chemotherapy, radiotherapy and surgery but still had a higher risk of death (103). Gliomas, especially GBM, have poor prognosis and palliative care is often the only option. An American study found that female patients are more often admitted to hospice to improve end-of-life care than males and that males stay in hospice for a much shorter time when admitted (104).

\section{Biomarkers of survival}

Apart from sex, the most important clinical prognostic factors for gliomas include patient's age, type of surgery and performance status $(12,20,45)$. Type of diagnosis is also of importance, and it is closely related to the age at diagnosis, as GBMs are often diagnosed in older patients, whilst AC and ODG are more common in younger patients. Maximal safe resection is preferred in all gliomas over a biopsy, regardless of molecular subtype (12). Genetic alterations, currently used to define the diagnostic entity, namely $I D H 1 / 2$ mutations and $1 \mathrm{p} / 19 \mathrm{q}$ codeletion, were shown to have predictive value for gliomas, especially for patients treated with a combination of procarbazine, lomustine and vincristine $(105,106)$. For 
LGG, IDH1/2 mutations and 1p/19q codeletion also had prognostic value, and this observation led to the updated brain tumor classification, valid today $(32,41)$.

The greatest struggle to extend the survival of patients concerns GBM. Unfortunately, a recent meta-analysis did not show any improvement in the 5-year survival rate for GBM over the past 15 years, when focusing on patients who survived at least 2 years (107). However, the same study showed increasing number of patients reaching 2- and 3-year survival over the studied period (107). Having cohorts with too few long-term survivors is the main issue for successful analysis of the factors that predispose to the exceptionally long survival. Despite the obstacles, a few reports are available, suggesting the importance of clinical and molecular biomarkers. A great hope is put in the ETERNITY study (EORTC 1419), which collects data about patients with survival over 5 years from centers in Europe, US and Australia. The first results presented at the American Society of Clinical Oncology (ASCO) meeting in 2019 showed that MGMT promoter methylation and gross total resection were favorable factors and median age of included patients was 52 years, which is lower than average for a population-based cohorts (108). However, we will have to wait for a full analysis of molecular and clinical factors.

One of the studies investigating factors associated with long survival revealed that survival of 3 years or longer is predominantly associated with younger age ( $<50$ years) and MGMT promoter methylation, although tumors with staining of Ki-67 below 20\%, a nuclear protein and marker of proliferation, also seemed to have a better chance for longer survival (OR: 3.07; 95\% CI: 1.15-8.29; $\mathrm{p}=0.026$ ) (109). Another study, which compared patients with survival below 1 year and longer than 3 years, showed that age ( $<60$ years, $p=0.001)$, total resection $(\mathrm{p}<0.001)$ and tumor localization (no contact with $\mathrm{SVZ}, \mathrm{p}=0.05)$ were predictors of long survival (110). With age being such a strong prognostic factor, some tried to answer, whether there are cellular programs that differ between younger and older patients. Bozdag et al. suggested that tumors of older patients have a signature of genes involved in angiogenesis and response to hypoxia and that age-based differences can be found on the genetic, transcriptomic, and epigenetic level (111). A recent study showed that the most common type of mutation in GBM is a $\mathrm{C}>\mathrm{T}$ substitution, closely related to aging, and that mutational profiles of gliomas largely depend on the patient's age, e.g. there is association between EGFR-gains and loss of CDKN2A in GBM and mutations in ATRX in LGG (4). The inability of cells to repair damaged DNA is believed to be a major cause of aging (112), which further supports the strong position of age as a prognostic factor. For GBM tumors, single nucleotide variant count increases at an average of 0.018 mutations per megabase per year (4).

The use of epigenetic signatures to select patients with a better prognosis was proposed by several research groups $(43,113,114)$. With the current knowledge, a striking majority of GCIMP tumors harbors $I D H 1 / 2$ mutations. Before the inclusion of $I D H 1 / 2$ mutations into the glioma classification scheme, high-grade gliomas with $I D H$ mutations were often treated and analyzed together with the current diagnostic group of GBM. Analysis of methylation profiles of long- and short-term survivors from such a mixed cohort identified a G-CIMP profile as a prognostic biomarker of long survival, which was additionally associated with IDH (115). Single CpG loci in homeobox gene family (HOXD8, HOXD13 and HOXC4), transcription factors (NR2F2 and TFAP2A) and a Wnt pathway negative regulator (Dickkopf2) were also proposed in this study as a mean to distinguish long- and short-term survivors. More groups 
explored the use of DNA methylation analysis to select GBM patients with better prognosis, but the suggested biomarkers seemed to be true only for the specific study $(113,114)$.

Seizures are a common and unpleasant symptom accompanying brain tumors, but surprisingly, seizure presentation at diagnosis was found to be associated with longer survival of GBM patients, regardless of treatment for seizure management (116). However, these results should be considered cautiously, due to inclusion of a small group of patients with IDH mutations. 


\section{Aims}

The generalized aim of the studies included in this thesis is to find biomarkers associated with sex differences, treatments and survival of glioma patients, which could contribute to further development of personalized glioma patient care.

The specific aims for this thesis are:

- To identify molecular biomarkers on sex chromosomes associated with sex differences in GBM (Paper I \& III)

- To investigate the role of $M G M T$ promoter methylation in GBM sex disparity (Paper II)

- To identify prognostic and/or predictive methylation-based biomarkers for patients treated with TMZ or RT (Paper IV) 


\section{Comments on Materials and Methods}

A detailed description of materials and methods used in Paper I-IV can be found in the appropriate section of each paper. Only brief comments on the most relevant methods can be found here.

\section{Patients and samples}

Patient material used in all studies included in this thesis was collected upon signed informed consent and in accordance with the ethical permissions as stated in Papers I-IV. All studies were conducted retrospectively, and each study included data from TCGA as an additional/confirmatory cohort, which is especially important when analyzing biomarkers in limited sample sized cohorts. Samples used in Paper I and III were collected consecutively since 2008 at Linköping University Hospital but few samples from the period 2004-2008 were also included. Patients included in Paper IV were selected from a randomized trial and cohorts included in Paper II were from the randomized trial and a consecutive collection at Linköping University Hospital. All tumors were routinely characterized for $I D H 1 / 2$ and TERT mutations with Sanger sequencing, in addition to the diagnostic analysis performed by the pathologists.

\section{Droplet Digital Polymerase Chain Reaction (ddPCR)}

The idea behind droplet digital PCR (ddPCR), which is the use of limiting dilution for quantitative PCR amplification detection, was first published in 1992 (117). The microfluidic system for ddPCR analysis, currently used worldwide and used in the analyzes described in Paper I and III, was commercialized by BioRad in 2011, with subsequent updates and automation of sample preparation.

In principle, ddPCR is a step-up from the standard quantitative real-time polymerase chain reaction (q-PCR), which uses a fluorescent signal to measure amplification of DNA. This also defines the array of possible applications for ddPCR, e.g., analysis of gene copy number $(\mathrm{CN})$, relative and absolute gene expression, detection of rare mutations, quantification of libraries for next generation sequencing and quantification of viral load (118-120). Amplification of the target is detected either with fluorescently labelled TaqMan probes or with a fluorescent dye EvaGreen. Many suppliers offer optimized, ready-to-use primers and probes, however, it is also possible to design them in-house using freely available online tools. Each sample is partitioned into 20,000 droplets (water-oil emulsion). Reagents necessary for target amplification are in the aqueous phase of the droplets, together with the fragmented and randomly dispersed DNA template. After end-point PCR, each droplet is passed through a reader to determine whether amplification occurred (positive droplets) or not (negative droplets), by measuring the fluorescence signal. Finally, the fraction of positive droplets is fit into Poisson distribution to return the concentration of target DNA in the analyzed sample.

ddPCR was used in Paper I and III to analyze copy number $(\mathrm{CN})$ alterations and relative mRNA gene expression. Each experiment was based on a comparison of the amplification of a target to a reference, whether it was a gene with 2 stable copies for $\mathrm{CN}$ analysis or stable mRNA expression for gene expression analysis. In Paper I, we used probes targeting 10 genes spread throughout chromosome $\mathrm{Y}$ and analyzed their $\mathrm{CN}$ alterations. If deletion was detected in all of them, we assumed a loss of chromosome Y (LOY). Previously, we used a similar approach to detect $1 \mathrm{p} / 19 \mathrm{q}$ co-deletion in glioma samples (121). 
Formalin fixed, paraffin embedded (FFPE) samples are often used for biomarkers studies, as it is the easiest way to archive them. Unfortunately, such sample preparation leads to poor quality and fragmentation of DNA. The ddPCR method is suitable for analysis of DNA from FFPE samples, as amplicons are rarely longer than 100 base pairs. Additionally, thanks to the high sensitivity and low input requirements, ddPCR is now often considered for liquid biopsy analyzes $(50,122)$.

\section{Methylation arrays}

Methylation of mammalian DNA occurs at cytosines followed by guanines, called $\mathrm{CpG}$ sites. Methylated $\mathrm{CpG}$ sites are in general a sign of inactive chromatin and accumulation of $\mathrm{CpG}$ sites is often found at the transcription regulatory regions, that is gene promoters.

As mentioned before, DNA methylation is an important part of biomarker research in brain tumors- methylation of the $M G M T$ gene promoter is used as a predictive biomarker for treatment with TMZ (123) and genome-wide methylation profiles can be used to aid tumor classification (35).

The proof of concept for the genome-wide methylation analysis using microarray technology has been published in the early 2000s (124). Over the years, not only has the number of CpG sites included in the microarray design increased, but there has also been an incredible development of bioinformatics tools for data analysis.

In Paper IV, we used the Infinium MethylationEPIC BeadChip arrays, which allow for quantitative interrogation of over 850,000 methylation sites in each sample. The protocol (Figure 5) starts with bisulfite conversion of DNA extracted from cells or tissue (snap frozen and FFPE material is suitable). During this process methylated cytosines remain intact and unmethylated cytosines are deaminated to uracil. In a subsequent genome-wide amplification, during the synthesis of a new strand, methylated cytosines are paired with guanine and uracil with thymine, resulting in changes to the original DNA sequence. Next, DNA is fragmented, purified through isopropanol precipitation, and then resuspended in a buffer. In this form samples are loaded onto arrays and DNA hybridizes to the complementary oligonucleotides (probes) attached to the surface of immobilized beads. Each bead is coated with oligonucleotides specific to one locus. In the next step, probes are extended by a single, chain terminating dideoxynucleotide, based on the complementarity to the bound DNA fragment. Incorporated dideoxynucleotides are labelled with biotin (guanine and cytosine) or dinitrophenyl (DNP) (adenine and thymine) and labels will allow to distinguish between genotypes. Next, DNA fragments are removed, and the staining process begins. Green, fluorescent streptavidin binds to biotin and the red fluorescent anti-DNP antibody binds to DNP. Additional rounds of staining allow for amplification of fluorescent signal. After the staining process, arrays are imaged on the scanner and data is collected in the raw intensity files, also called idat files. These files are compatible with the methylation-based classifier available online (35) and can be used for further analysis, e.g., differential methylation analysis, as described in detail in Paper IV. 


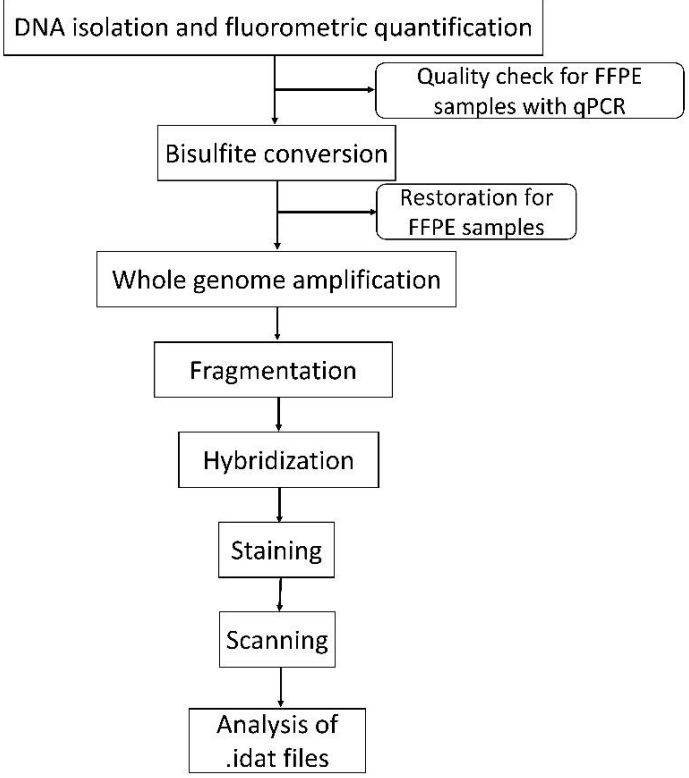

Figure 5. A flow-chart representing processing of the samples during Illumina's methylation array analysis. This method is suitable for snap frozen and FFPE samples, but the latter require small modifications of the protocol. After DNA isolation, DNA degradation from FFPE samples is assessed through a qPCR run and compared to a control DNA. The additional restoration step for FFPE samples provides larger fragments for the following whole genome amplification.

\section{Maximally selected rank statistics}

When using continuous data as a biomarker, such as gene expression, an appropriate cut-off point must be selected for clinical decisions to be made. For this purpose, the most common is to use arbitrary dichotomization, dividing the data by the median, quartiles, or the mean value of the expression (125). Even in the case of the already extensively studied effect of $M G M T$ promoter methylation on survival of GBM patients $(44,45)$, there is still no clear consensus on the value of the cut-off point for the methylated and unmethylated tumors (126). The method of maximally selected rank statistics allows for dichotomization of quantitative, ordinal and censored data $(127,128)$. First, we assume a simple relationship between the $X$ quantitative variable and the $Y$ response variable, where the value of the quantitative variable determines creation of the two groups in the response variable (one with $X$ values below or equal to the cut-off point and one with $X$ values above the cut-off point). In Papers I and III, the method was used to find the best cut-off points for the quantitative factors (mRNA gene expression, $\mathrm{CN}$ data) that separated the response variable (OS of the patients). For each possible value of the $X$, the standardized log-rank statistics is calculated, and the highest value of the standardized log-rank test indicates the best cut-off point (Figure 6). It is important to define reasonable sizes of the two groups, e.g., not to allow for one group to be smaller than $10-20 \%$ of the studied population. 

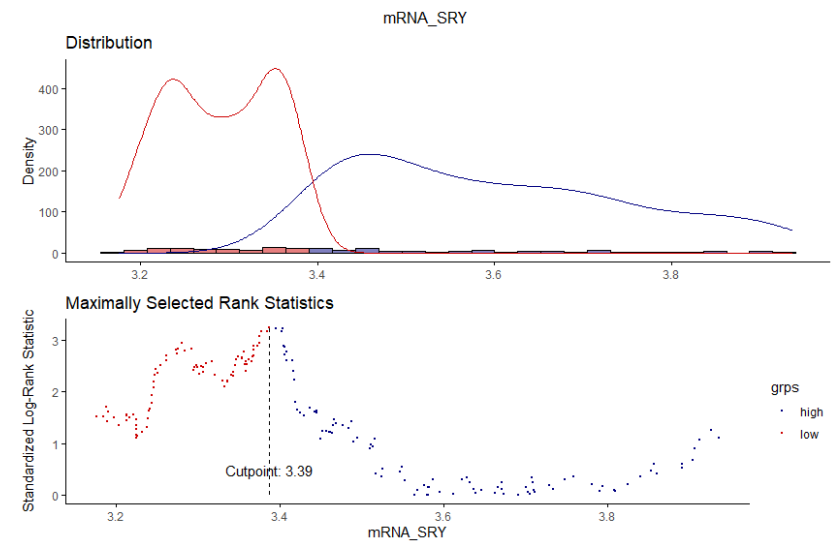

Figure 6. An example of the application of maximally selected rank statistics from Paper I. The normalized mRNA expression values of the SRY gene obtained from microarray data were used as the $X$ quantitative data and the OS served as the $Y$ response data. For each value of $X$, the standardized log-rank statistic was calculated using the maxstat package in R 3.6.0, RStudio version 1.3, and the highest value of standardized log-rank statistic corresponded to the cut-off point of $S R Y$ mRNA expression 3.3867( $\log 2)$. The obtained dichotomization revealed survival differences between patients with low and high SRY expression (11.9 vs. 14.7 months, respectively). 


\section{Results and discussion}

\section{Paper I}

The existing male dominance observed in GBM patients is a complex outcome of many factors. In Paper I, we report on our findings from a retrospective, cross-sectional study about loss of chromosome Y (LOY) in male GBM, CN changes of the 10 selected genes from the $\mathrm{Y}$ chromosome (Figure 7a) and the influence of both on OS.

Patient material for $\mathrm{CN}$ analysis with ddPCR, blood and FFPE tumor tissue, was collected in the South-East Sweden hospital region between 2008-2016. These patients, referred to as a Swedish cohort, were from a previously published study and all had confirmed GBM, IDH wild-type tumors (129). All were treated with TMZ concomitant with RT. Tumor samples for 105 patients and 61 matched blood samples were available. The second cohort was derived from TCGA collection and consisted of transcriptome data of 219 male primary GBM, IDH wild-type, accessed via the GlioVis portal $(130,131)$. Correlation between changes in the copy number of genes in the Swedish cohort, the expression level of these genes in the TCGA cohort and OS was tested with Kaplan-Meier log-rank analysis after choosing the best cut-off value with maximally selected rank statistics.

The $\mathrm{CN}$ analysis of the $105 \mathrm{GBMs}$ revealed that chromosome $\mathrm{Y}$ was subjected to various gene dosage alterations. We found deletions and amplifications of the tested genes, but unidirectional changes of all markers were found only in 6 samples for deletion and 4 for amplification (Figure 7b). Our study revealed that deletion of the sex determining region $\mathrm{Y}$ $(S R Y)$ gene significantly correlated with shorter OS (10.8 vs. 14.8 months, $\mathrm{p}=0.0031 ; \mathrm{n}=104)$ (Figure 7c) and in the multivariate analysis, which included age, preoperative performance status, MGMT promoter methylation status and type of surgery, $S R Y$ deletion had the strongest effect on survival (HR=3.352; 95\% CI: 1.695-6.629; $\mathrm{p}=0.001)$. Further, we showed that these changes were almost exclusively present in the tumor tissue and not in the peripheral blood and were not age dependent. Deletions of all markers, considered as a LOY, also correlated with significantly shorter OS of the patients ( 7 vs. 14.5 months, $\mathrm{p}=0.0016$; $\mathrm{n}=94$ ) (Figure 7d).

From the analysis performed on TCGA cohort, which tested the correlation between mRNA expression of the 10 markers on chromosome $\mathrm{Y}$ and patient survival, we were able to confirm the link between SRY and reduced OS. Median OS for patients with low SRY expression was 11.9 months and for those with high expression 14.7 months $(\mathrm{p}=0.00069)$. The significantly shorter OS was also associated with low expression of TMSB4Y (12.6 vs. 15.8 months, $\mathrm{p}=0.0023), A M E L Y$ (12.7 vs. 14.2 months, $\mathrm{p}=0.0087)$ and $U T Y$ (12.7 vs. 18.5 months, $\mathrm{p}=0.0031$ ). Interestingly, through the gene set enrichment analysis we showed that low expression of $S R Y$ was associated with several signaling pathways involved in GBM development, e.g., EGFR, PDGFR and Myc (34).

There were no data available on the prevalence of LOY or deletions of specific genes of chromosome Y among GBM patients, hence the cross-sectional design seemed suitable. In the first study reporting on LOY in the peripheral blood of the elderly men from the Uppsala Longitudinal Study of Adult Men, LOY was found in $8.2 \%$ of the cohort (132). Another study on head and neck cancer revealed LOY in $28.6 \%$ of tumors (133). This influenced our lack of 
prior power calculations, which are otherwise highly desired in biomarker studies exploring the relationship of the biomarker with survival.

a

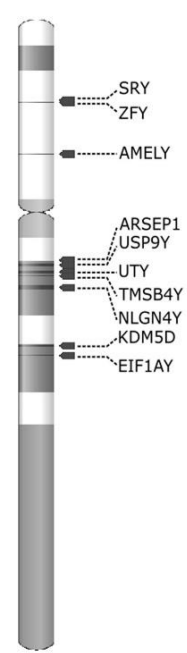

b

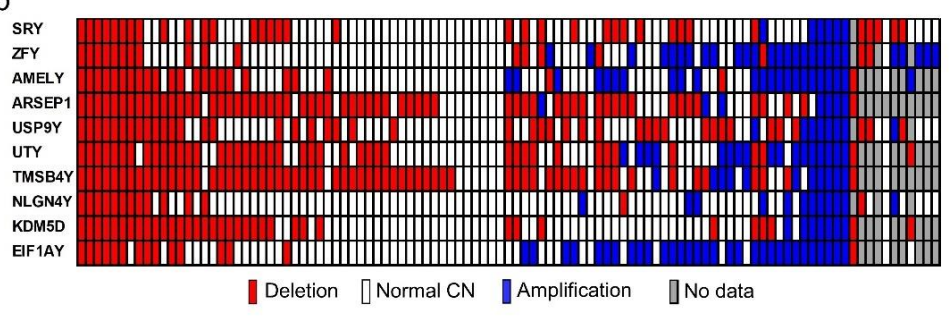

C

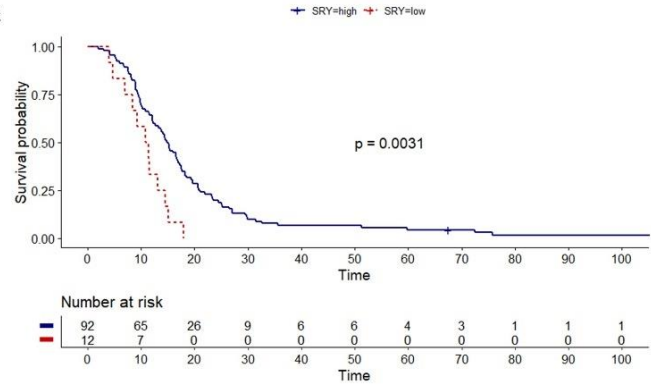

d

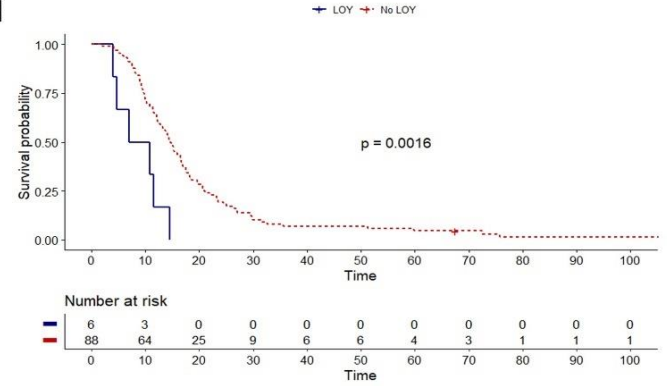

Figure 7. Deletion of markers on chromosome $\mathrm{Y}$ and LOY are associated with shorter survival of male GBM. Representation of the markers tested with ddPCR on chromosome Y (a). All 10 markers were successfully analyzed in 94 samples; deletions were detected with the cut-off $\mathrm{CN}<0.8$ (red) and amplifications with the cutoff $\mathrm{CN}>1.2$ (blue) (b). Maximally selected rank statistics was used to investigate the relationship between the $\mathrm{CN}$ of genes and OS, and Kaplan-Meier analysis in (c) shows that deletion of $\operatorname{SRY}(\mathrm{CN}<0.6)$ was associated with shorter OS (10.8 vs. 14.8 months). LOY was defined as deletion of all 10 markers and was detected in 6 samples. These patients also had shorter OS (7 vs. 14.5 months) (d). SRY-sex determining region Y, ZFY- zinc finger protein Y- linked, AMELY- amelogenin Y-linked, ARSEP1- arylsulfatase L pseudogene 1, USPY- ubiquitin specific peptidase 9 Y-linked, UTY-ubiquitously transcribed tetratricopeptide repeat containing, Y-linked, TMSB4Y- thymosin beta 4 Y-linked, NLGN4Y- neuroligin 4 Y-linked, KDM5D- lysine demethylase 5D, EIF1AY- eukaryotic translation initiation factor 1A Y-linked.

It may also be viewed as a disadvantage to analyze deletions on the DNA level in one cohort and mRNA expression as the approximation of the loss in the other. Ideally, the confirmatory 
cohort should be treated in the same way as the discovery cohort, with the exact same analyses performed. However, deletions commonly lead to reduced mRNA expression of the gene, hence, we looked for a similar effect of both on OS. Also, eight out of ten markers used here had a good correlation between gene expression and $\mathrm{CN}$ in a study based on head and neck squamous cell carcinoma (133). The approach of using markers spread throughout the chromosome was previously used by Mitchell, et al. (134) but a disadvantage of our methodology was the use of one reference probe, as it is often advised to use two or more. Extreme downregulation of chromosome $\mathrm{Y}$ expression has been shown before as a risk for glioma development and was associated with EGFR amplifications and EGFR overexpression (135). Wright, et al., showed that LOY is associated with 19 autosomal genetic regions, which also associate with loss of chromosome $\mathrm{X}$ in females (136). In a different study, a group of genetic variants associated with LOY occurrence was identified in the proximity of common cancer related genes, like CHEK2 or TERT (137). The same genetic variants led to increased risk of glioma (OR 2.36; 95\% CI: 1.34-4.17; $\mathrm{p}=0.004)$ and when tested in women, they were associated with increased risk of breast, ovarian and endometrial cancer. These results support the presence of a generalized genetic instability related to the occurrence of LOY. Although LOY and SRY deletions are not common events in GBM, both strongly correlated with decreased OS, suggesting their prognostic value for male GBM patients.

\section{Paper II}

Methylation status of the $M G M T$ promoter is a known predictor of successful TMZ treatment $(44,45)$ but has not been systematically investigated for possible sex differences. Few studies pointed towards a higher prevalence of $M G M T$ promoter methylation in females, which could be the reason for the better results observed among females $(56,76)$. In Paper II we report on the re-analysis of two published GBM cohorts and a TCGA-derived cohort, for which we assessed sex disparity of MGMT promoter methylation, OS, and the associations between them.

The first cohort consisted of 342 patients from the Nordic trial, for whom MGMT status was available for 203 (45). The randomized Nordic trial compared three treatment arms, TMZ given in up to six 4 weekly cycles $\left(200 \mathrm{mg} / \mathrm{m}^{2}\right.$, day $1-5$ every $28^{\text {th }}$ day) vs. standard RT $60 \mathrm{~Gy}$ administered over six weeks vs. hypofractionated RT of 10 fractions of $3.4 \mathrm{~Gy}$ to the final dose of 34Gy. In the second cohort, there were 179 GBM, IDH wild-type patients, all treated with postoperative RT concomitant with TMZ, and $M G M T$ promoter methylation status was available for all (129). Lastly, in TCGA collection, we identified 257 GBM, IDH wild-type patients with known MGMT status and 189 of them were treated with an alkylating agent (TMZ or nitrosourea), which is of importance for the MGMT methylation status and survival assessments.

Despite a lower number of females in all three cohorts, we found a higher proportion of methylated MGMT tumors among them (48\%-59\% in females vs. 33\%-36\% in males, $\mathrm{p}<0.05)$. In the Nordic trial cohort, $M G M T$ promoter methylation status was predictive of survival only in the TMZ arm and we noted only a borderline survival benefit for females (Figure 8a). In the multivariate analysis performed separately for males and females from the TMZ arm, which included MGMT status, preoperative performance status, age and type of surgery, we found that tumor resection was associated with longer survival for females 
( $\mathrm{p}=0.017)$, and methylated MGMT ( $\mathrm{p}=0.013)$ with preoperative performance status $(p<0.0001)$ were associated with longer survival in males.

a

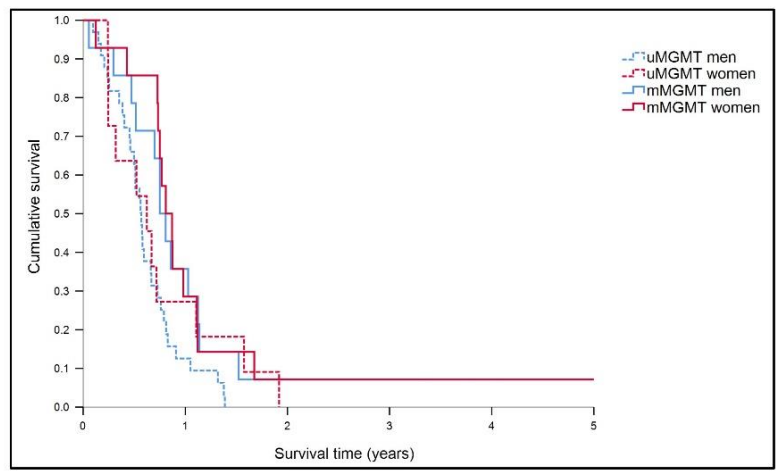

b

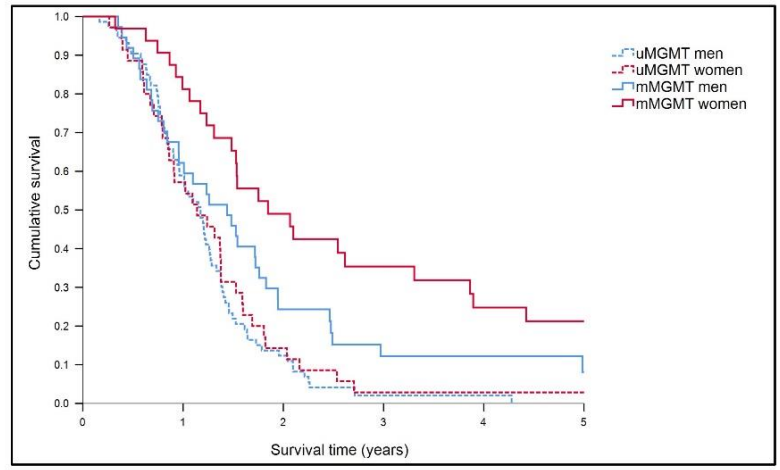

$\mathrm{C}$

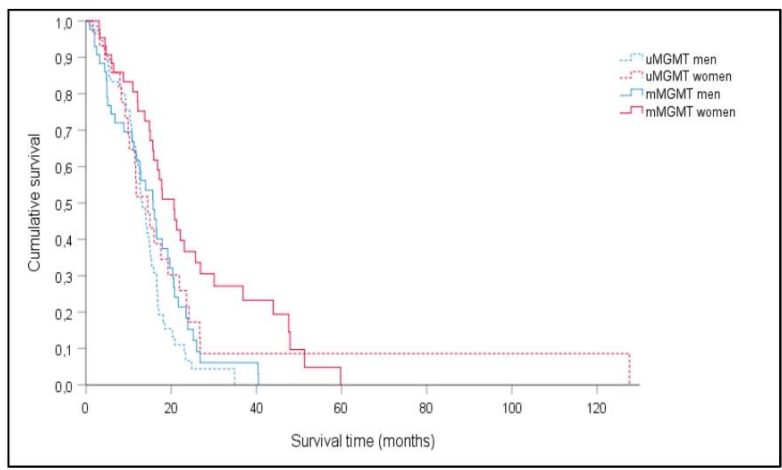

Figure 8. Survival curves for females and males with different $M G M T$ promoter methylation status. Survival analysis was done with the Kaplan-Meier log rank method for the TMZ arm $(n=72)$ of the Nordic trial and longest survival was found for females (9.7 months, CI7.5- 11.9) and males (9.0 months, CI7.4-10.6) with methylated MGMT, compared to females (7.5 months, CI2.9-12.0) and males (6.8 months (CI5.8-7.9) with 
unmethylated MGMT but differences did not reach statistical significance $(\mathrm{p}=0.056)$ (a). In the population-based cohort treated with radiochemotherapy females with methylated MGMT had the longest survival of all groups and the differences were statistically significant $(\mathrm{p}=0.0002)(\mathrm{b})$. Similarly, we found a significant survival difference between males and females treated with an alkylating agent with mMGMT in the TCGA cohort $(\mathrm{n}=189, \mathrm{p}=0.004)$ (c). uMGMT- unmethylated MGMT promoter, mMGMT- methylated MGMT promoter.

In the population-based cohort, a female survival benefit was noted already in the analysis stratifying patients only by sex, which was further strengthen by the separation according to the MGMT status (Figure 8b). Multivariate analysis again showed a strong association between tumor resection and survival for females (radical surgery vs. biopsy/partial resection HR: 0.33 , 95\% CI: 0.13-0.84; $\mathrm{p}=0.02$ ), whereas methylated MGMT correlated with longer OS in both sexes (males: $\mathrm{HR}=0.61,95 \%$ CI: 0.4-0.94, $\mathrm{p}=0.024$; females: $\mathrm{HR}=0.39,95 \% \mathrm{CI}: 0.22$ $0.70, \mathrm{p}=0.0014)$.

Results from the TCGA cohort revealed longer survival of females with methylated MGMT in comparison to the rest of the cohort $(n=257$, females with methylated MGMT vs. females with unmethylated MGMT vs. males with methylated MGMT vs. males with unmethylated MGMT; 17.2 months vs. 11.8 months vs. 12.7 months vs. 12.6 months, respectively, $\mathrm{p}=$ 0.01). This was also true in the analysis which only included patients treated with alkylating agents $(\mathrm{n}=189)$ (Figure 8c).

The results of this study confirmed a higher proportion of MGMT methylated tumors in females. In the population-based cohorts we found that females had a survival benefit even if MGMT status was not included, a result not observed in the Nordic trial. Recent data from CBTRUS and a Swedish National Quality Registry for Primary Brain Tumors also do not support the overall survival benefit in females $(10,57)$. It should be pointed out though, that the Nordic trial only included patients 60 years or older, whilst the other two cohorts consisted of younger patients as well. A recent US based study showed that in all age groups $(0-80+)$ there is a higher incidence of GBM in males but the survival advantage for females disappears for patients 70 years or older (83). We did not observe an age influence on OS in the multivariate analysis performed in the Nordic cohort, but the analyzed groups were small. At the same time, in our population-based cohort, patients were divided by the median age (58 years for males and 59 years for females), making it difficult to capture the effect. However, the correlation between sex and age should be considered for future studies.

Another limitation that should be considered is that MGMT methylation was measured with a different method in each cohort, which may cause discrepancies, especially with the lack of consensus for the cut-off distinguishing methylated tumors from the unmethylated ones (126).

In summary, this study showed that females have $M G M T$ promoter methylated tumors more frequently than males and MGMT tumors are associated with better survival. We also demonstrated the importance of considering a subgroup analysis to elucidate potential sex differences in glioma patients. Such analyzes are increasingly required and the data from already published studies can be a valuable source for investigation. 


\section{Paper III}

Sex chromosomes are commonly understudied due to the abundance of repetitive sequences and problems with handling compensation for gene dosage differences. The AR coding gene is located on chromosome $\mathrm{X}$ and before this study was initiated, several published papers have already shown overexpression of AR in GBM and the promising effects of AR inhibition (86, 138-140). However, molecular analyses were limited to CN and mRNA/protein expression analyzes, without extensive exploration of sex differences. Therefore, in Paper III, we focused on many of the AR-oriented molecular analyzes in GBM and the correlation between their results and OS in a sex-specific way.

We used samples collected consecutively at Linköping University Hospital, as well as data from TCGA database. The local sample collection consisted of 179 FFPE GBM from a previously described cohort (129), with DNA available for 170 of them. These samples were used for $\mathrm{CN}$ analysis. For further $\mathrm{CN}$ analysis, as well as gene expression and AR promoter methylation analysis, we used 91 fresh-frozen samples. We also had access to 167 blood samples from GBM patients that were mostly matched with FFPE and fresh-frozen tumor samples. Patients overlapped between these groups and in 23 cases, samples from the same patient were found in all three cohorts. Blood samples were used to analyze the number of trinucleotide repeats (CAG) in exon 1 of AR.

From TCGA, we included 354 samples from primary, IDH wild-type GBM tumors with transcriptomic data available.

By using ddPCR, we established changes in the CN of $A R$ in FFPE and fresh-frozen samples and found that GBM tumors harbor deletions and amplifications of the AR gene, which are more common in females. In males, $\mathrm{CN}$ correlated with $A R$ mRNA expression, but the same relationship was not found in females. Nonetheless, $A R$ mRNA expression was enhanced in GBM samples of both sexes, with no differences between males and females in either analyzed cohort. In the TCGA cohort the highest $A R$ expression was found in the classical subtype, according to the classification by Wang et al. (141) (Figure 9a). The CN alterations of the AR gene were previously reported by Zalcman et al., although they were more frequent than in our analysis, which most likely is caused by the methodological differences (138). Previous studies also found similar expression levels of AR in males and females $(138,142)$, but the more surprising result was increased testosterone levels in the serum of GBM patients (140).

Methylation of the promoter regions is responsible for regulation of gene expression. Here, methylation of $17 \mathrm{CpGs}$ upstream of the TSS of the $A R$ gene was analyzed with pyrosequencing combined with the gene expression results. Spearman correlation analysis revealed that methylation of different $\mathrm{CpGs}$ is linked with $A R$ expression in males and females. There were three $\mathrm{CpGs}$ found in females, where methylation negatively correlated with mRNA expression (chrX:67543502, chrX:67543517 and chrX:67543659). In males, significant negative correlation was found for chrX:67543299 and chrX:67543895. 
We used TCGA gene expression data to check whether $A R$ expression has influence on the survival of males and females. For the potential cut-off selection, we used maximally selected rank statistics (as in Paper I), followed by the log-rank Kaplan-Meier analysis. This revealed that high $A R$ expression in females was associated with shorter survival (high vs. low $A R$ mRNA expression, 13.6 vs.15.7 months, $\mathrm{p}=0.035$ ) (Figure 9b). Surprisingly, the association between $A R$ expression and OS was the opposite in males and high $A R$ expression correlated with better outcome (high vs. low $A R$ mRNA expression, 16.6 vs.12.2 months, $\mathrm{p}=0.04$ ) (Figure 9c). This was an important finding, as in the analysis combining both sexes, there was no correlation between gene expression and survival.
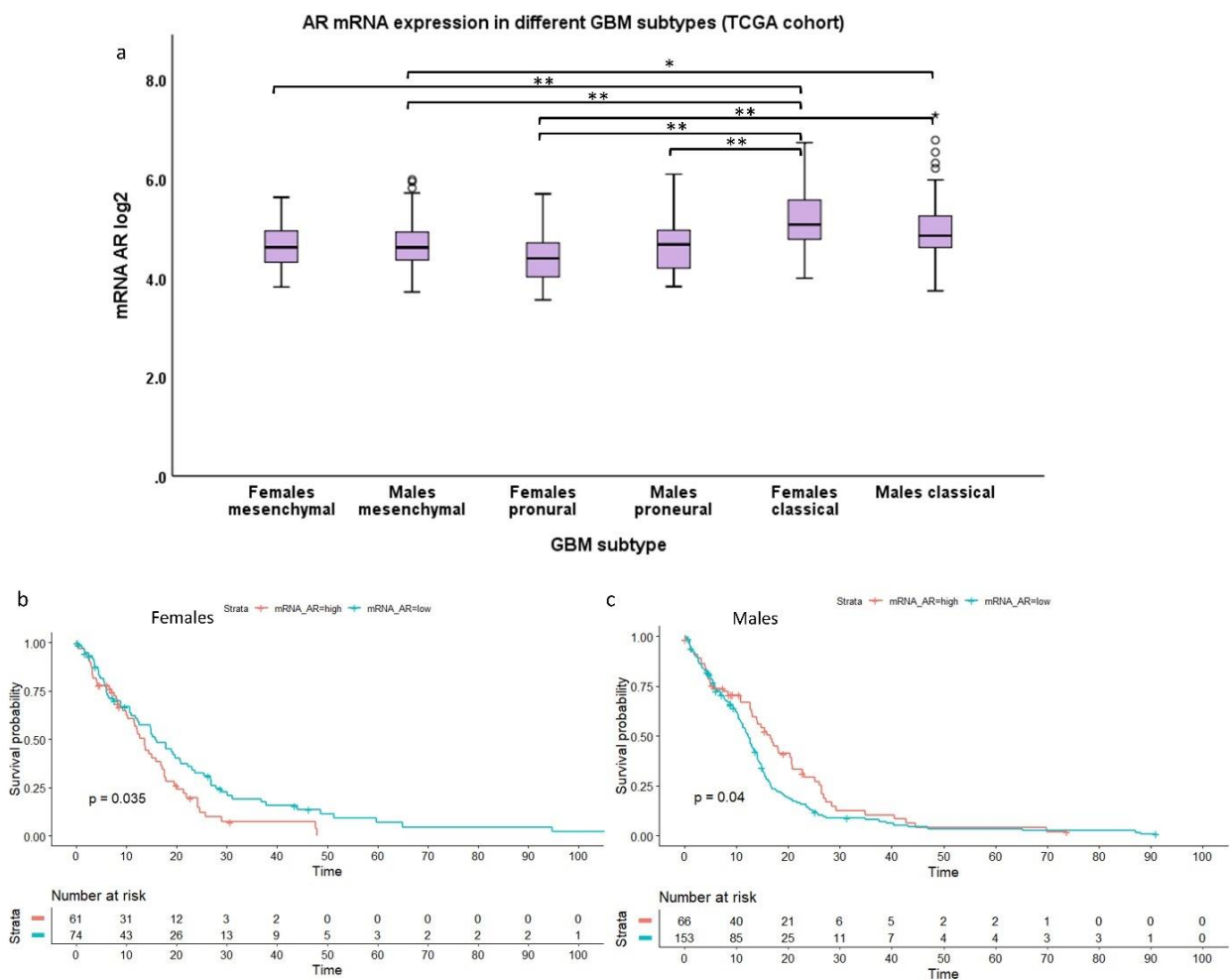

Figure 9. AR mRNA expression in GBM samples from TCGA cohort divided by subtypes and patients sex (a) and Kaplan-Meier curves for females (b) and males (c) with low and high AR mRNA expression divided by cutoff values indicated by maximally selected rank statistics. *p<0.05; ** $<0.005$

AR regulates the expression of many genes, and to reveal the differences between males and females, we decided to go for the gene set enrichment analysis, to try to find pathways associated with high AR expression that may be involved in creating the sex differences among GBM patients. The only significant result was the enrichment of DNA repair genes in male high AR-expressing samples. The same set of genes, although present in the analysis of the female samples and $\mathrm{p}<0.05$, had a high false discovery rate $>50 \%$. These findings were strengthened by the positive correlation between AR protein expression and expression of proteins involved in the DNA repair mechanism (p53, Rad50, Chk1). In prostate and breast cancer, AR signaling mediates resistance to RT and use of antiandrogens improves the 
outcome $(143,144)$. A study by Werner et al., showed that use of antiandrogens in ARpositive GBM cell lines and mouse xenograft models helped to overcome radioresistance, which has important clinical implications (86).

The coding region of exon 1 of the $A R$ gene contains a highly polymorphic stretch of polyglutamine-coding CAG repeats (145). The number of repeats ranges from 6 to 39 in healthy individuals. AR binds to DNA via the zinc-finger domain and interacts with coactivators or co-suppressors of transcription. The length of the polymorphic region influences the transactivation capacity of AR and interaction with the mentioned co-factors (145). As prostate cancer is largely dependent on AR signalling, a study of CAG repeats showed increased risk of prostate cancer with lower numbers of CAG repeats (146). This prompted us to the analysis of CAG repeats in the DNA extracted from the blood of GBM patients. We used capillary electrophoresis and fragment length analysis of the amplified polymorphic region and compared results obtained from GBM patients $(n=167)$ with the results from a cohort of healthy individuals ( $n=799)$, but no differences could be found. This led to the conclusion that there is no association between the number of CAG repeats and risk of GBM.

The main take home message from this study was that $A R$ mRNA expression is associated with survival of GBM patients in a sex dependent manner, despite no differences in the expression between sexes. The $\mathrm{CN}$ alterations of the $A R$ gene are common in GBM, but they do not influence the patient's OS.

\section{Paper IV}

The only known predictive biomarker for TMZ treatment in GBM patients is MGMT promoter methylation and no biomarkers are available for predicting response to RT (44, 123). Elderly patients, unfit for radiochemotherapy, can be treated with TMZ or RT alone, depending on the $M G M T$ promoter methylation status $(13,14)$. However, the outcome of treatment varies even for patients with the same prognostic factors and the knowledge here is scarce.

Material from the Nordic trial, which compared three treatment arms (TMZ vs. hypofractionated RT 34Gy vs RT 60Gy), was used in Paper IV to try to find methylationbased biomarkers that could help identify patients with expected long or short survival for the same treatment modality and with the same prognostic factors. In the study in total, 59 patients were included, 20 from the TMZ and 34Gy arms respectively and 19 patients from the arm treated with RT 60Gy. All patients had good performance status (WHO 0-1) and had undergone tumor resection. Patients were also chosen to represent the longest and the shortest survival from each treatment arm. Half from each subgroup had methylated MGMT. Tumor DNA was subjected to the analysis with Infinium MethylationEPIC BeadChip array for methylation profiling.

First, we checked which classes and subclasses were present in our samples using a methylation-based classifier (35). In 3 cases, the content of tumor cells was too low, and samples were classified as normal tissue or tumor microenvironment, which highlights the importance of using high-purity tissue for molecular analysis. The remaining samples, apart from one, were classified as GBM, IDH wild-type and 21 of them were assigned to one methylation subclass. In 34 samples more than one subclass was detected and this stands in line with studies reporting on spatial heterogeneity of GBM samples $(36,39)$. One sample 
was classified as pilocytic astrocytoma, which is a grade I tumor, without IDH mutations and with a very good prognosis (9). The mentioned sample was selected due to the long survival of the patient. Our finding shows the importance of integration of methylation-based classification into future clinical practice and clinical trials.

After removing the non-GBM samples, we examined the differentially methylated CpGs within each treatment arm and MGMT methylation group, but no differences were found. Then, we decided to remove samples with the cause of death related to complications (such as infections), as these most likely did not reflect the biology of the tumor itself. Finally, we selected samples of the 3 most-extreme values for long-term and 3 short-term survivors, respectively, from each treatment arm and MGMT methylation group and compared their methylation profiles for differentially methylated CpGs (DMCs). DMCs were found in the TMZ arm, with methylated MGMT; 34Gy, with methylated MGMT; 60Gy, with unmethylated MGMT and in the combined RT arm (34Gy+60Gy), with unmethylated MGMT. The structural annotation showed a similar distribution of DMCs throughout the genome in all groups (Figure 10) and we deemed that analysis important because cancers are known to display aberrant methylation patterns which are sequence and location specific (3). For instance, a recent report showed accumulation of hypermethylated $\mathrm{CpGs}$ in the $\mathrm{CpG}$ island regions of GBM and in LGG such accumulation was observed in the more distanced regions to $\mathrm{CpG}$ islands, namely $\mathrm{CpG}$ shores (3).

Due to the high numbers of DMCs and despite the very few samples, we followed with further filtration and looked only at the regions in the proximity to gene promoters (the $5^{\prime}$ untranslated region (5'-UTR) together with TSS200 and TSS1500) and with methylation $\beta$ values distanced by \pm 2 standard deviations from the mean value calculated for each analytical group. Filtered DMCs were transformed into differentially methylated genes (DMGs) and used in the pathway enrichment analysis. Consistent with previous reports was the finding of the hypermethylated Wnt signaling pathway in the long-term survivors, in the MGMT methylated tumors from the TMZ arm (115). The Wnt signaling pathway has been shown to be of importance in GBM due to its contribution to maintenance of GBM cancer stem cells and the role played in treatment resistance (147).

Chai et al. proposed a 31-gene methylation signature for patients with unmethylated MGMT that would benefit from TMZ (148). Unfortunately, we did not identify any DMCs for the MGMT unmethylated tumors from the TMZ arm with long-term survival. Sole RT is recommended for elderly patients unfit for combination treatment and with MGMT unmethylated GBM (13). Our analysis of the combined RT arms did not yield any DMCs which could define patients with long or short survival. However, a recent study based on TCGA and the Chinese Glioma Genome Atlas cohort of 50 patients treated only with RT suggested a predictive methylation signature (149). 

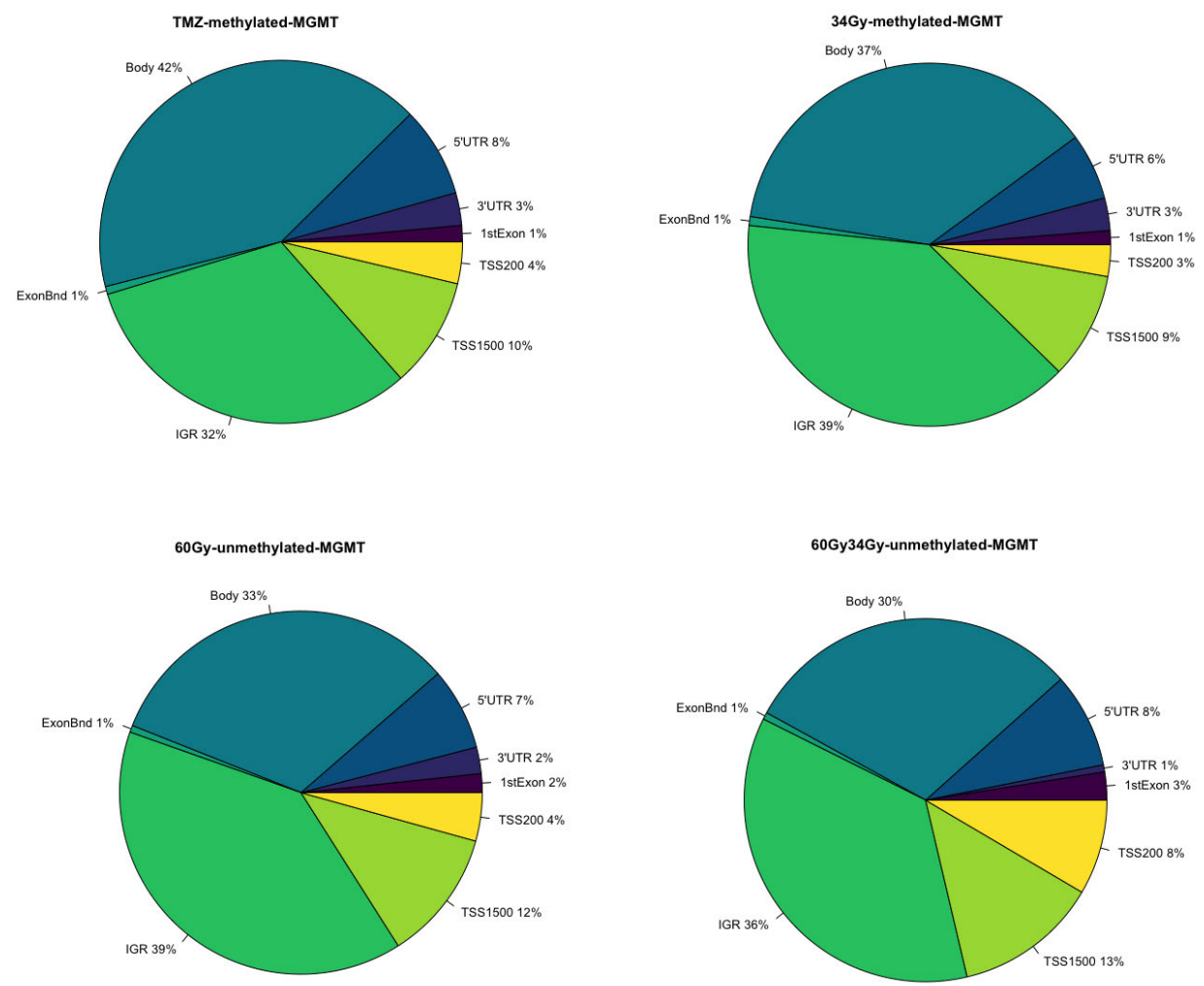

Figure 10. Distribution of structurally annotated DMCs found in different treatment groups. TSS200- 200 bases upstream transcription start site, TSS1500- 1500 bases upstream transcription start site, UTR-untranslated region, IGR- intergenic region

Aging of the tissue is reflected by the acquired epigenetic changes (150). As it has been pointed out several times throughout this thesis, GBM is tightly connected with age and aging-associated mutations (4), hence, we also found it appropriate to analyze the so called epigenetic age of the tumor samples. Three different algorithms were used for this purpose (150-152) and a common discovery for all of them was a trend towards lower epigenetic age of the short-term survivors in comparison to the long-term survivors from the same treatment arm and with the same MGMT status, although the differences were not statistically significant (Figure 11). Two studies, which also used a signature of $353 \mathrm{CpG}$ loci of Horvath's epigenetic clock showed that epigenetic age is associated with the molecular subtypes of gliomas and patients' survival $(153,154)$. Interestingly, one of the mentioned studies found epigenetic age acceleration of GBM samples (epigenetic age > chronological age) (154), which was in line with our results, and the other reported epigenetic age deceleration in GBM (epigenetic age < chronological age) (153). The PhenoAge and Hanmum's clocks $(151,152)$ used alongside Horvath's clocks in our study, also showed a common deceleration of epigenetic age. These discrepancies can be explained by differences in the models estimating epigenetic age and the heterogeneity of samples from published studies. 

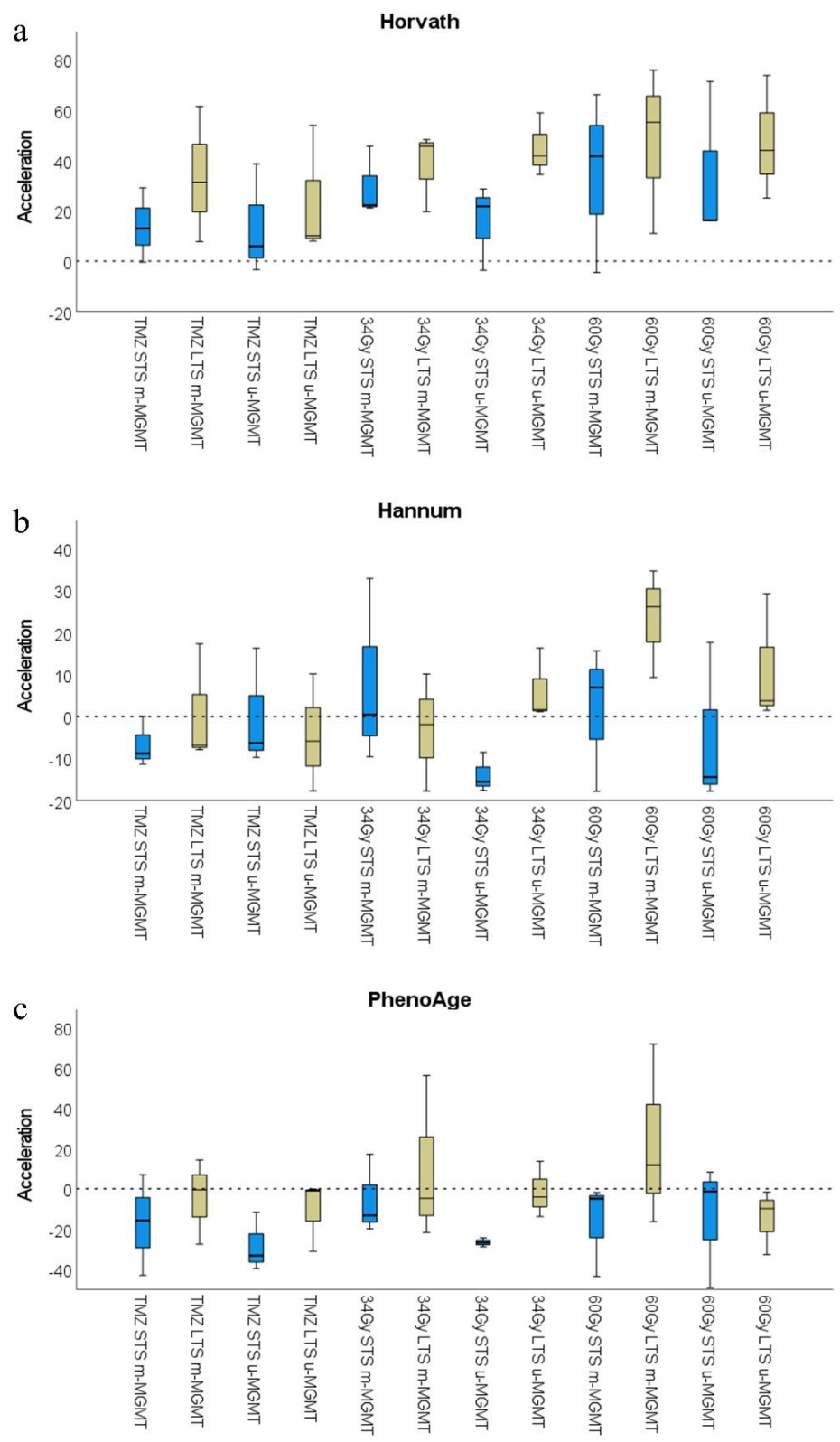

Figure 11. Epigenetic age calculated for long- and short-term survivors with different algorithms (Horvath (a), Hannum (b), PhenoAge (c)). Acceleration on the y-axis defines the difference between the epigenetic age and chronological age. LTS- long-term survivors, STS- short-term survivors, m-MGMT- methylated MGMT promoter, u-MGMT- unmethylated MGMT promoter

The results of this study require further evaluation and confirmation in a larger, well-defined cohort, because unambiguous conclusions should not be drawn from such a small number of 
samples. Despite this, they can still be considered valuable, as both, hypermethylation of the Wnt pathway in long-term survivors and epigenetic age deceleration in short-term survivors point towards the importance of stem cell programs in GBM. Not only gliomas have been shown to arise from the SVZ, where neural progenitor cells can be found (49), but also, the proximity of the tumor to SVZ was associated with patients' survival (110). Moreover, singlecell analysis of GBM revealed existence of cellular states linked to neurodevelopmental cell types and these cellular states were powered by the dysregulated epigenetic mechanisms (39, 155). 


\section{Concluding remarks and future perspectives}

Sophisticated, high-throughput technologies that have been developed in recent years and allow for rapid data acquisition and biomarker analysis. They also forced a shift from the analysis of a single biomarker to formulation of complex models with a great potential. The success of these changes, however, should be considered through the prism of changes that have been permanently introduced into clinical practice or are just one step away. Over a decade of intensive research, mostly focusing on single biomarkers, has led to an improvement in the brain tumor classification system, introduced in 2016 into the clinic (41). Thanks to technological development, just two years later, we were presented with an opportunity to improve this system through adding methylation profiling (156). Although the methylation classifier is not officially recommended as a diagnostic tool, it is already widely used to aid diagnosis in clinical trials or for problematic samples. A great example was presented in Paper IV, where one sample previously diagnosed as GBM, was in fact, with a methylation-based classification diagnosed as a pilocytic astrocytoma, a tumor with much better prognosis than GBM. To create a reliable classification system, there is a need for a tremendous number of samples and worldwide collaboration but with the freely available, ever-evolving classifier from the Heidelberg group, this may not be an obstacle. Methylation analysis can also be used for epigenetic age calculation and as presented in Paper IV and supported by other studies, epigenetic age could potentially serve as a quantitative prognostic biomarker for gliomas (153).

Accumulating evidence supports the use of certain biomarkers due to their prognostic and/or predictive value and newly registered clinical trials often use biomarkers as inclusion criteria, either focusing on patient groups with very limited choices or patients suitable for targeted therapies. We also observe a surge in the clinical trials that explore targeted therapies. One such phase 1 study explored the use of an inhibitor of mutant IDH1, ivosidenib, and showed a decrease in tumor size in $67 \%$ of 35 patients and a favorable influence on progression free survival in non-enhancing gliomas (157). Another phase 1 trial, NOA16, looked at a vaccine targeting IDH1 mutation (R132H) in 32 patients with grade 3 and 4 astrocytomas and found response in $93 \%$ of the patients, as well as a good safety profile of the treatment (158). Recently, genome-wide methylation profiles and other molecular biomarkers were found to be useful prognostic biomarkers in identifying patients with poor prognosis in the CATNON trial, which included non-codeleted $1 \mathrm{p} / 19 \mathrm{q}$ anaplastic gliomas treated with $\mathrm{RT} \pm$ concurrent and/or adjuvant TMZ (159).

As especially GBMs are fast growing tumors, the aim is to keep lead times as short as possible to reduce the time between radiologic diagnosis and start of oncological treatment. Methylation analysis could facilitate the diagnostic procedure by both determining the definitive diagnosis and provide information of biomarkers of importance to selection of therapy, such as $M G M T$ promoter methylation status. From my perspective, the real bottleneck for the use of the methylation classifier in clinical practice is the access to and cost of the analysis. The use of Illumina EPIC array, together with a robust methylation classifier, can deliver a final diagnosis within a week from surgery. Luckily, already today, we see alternatives that can reduce this time to below 24 hours, namely nanopore sequencing (160, 161). A nanopore sequencer uses a flow cell with hundreds of nanopores embedded in a dielectric membrane. Changes in the electrical current are recorded whilst single DNA or RNA strands, as well as their modifications are detected. This allows for a wide range of 
possible applications: DNA sequencing (gene panels, up to entire genome), methylation detection and RNA sequencing (162). Nanopore sequencing is also suitable for analysis of gene fusions which are understudied in gliomas but are an appealing treatment target (163, 164).

Important research into liquid biopsies for gliomas is also underway. Several studies have shown successful use of peripheral blood as liquid biopsy for early detection and profiling of distant cancer (e.g., GBM, pancreatic cancer, non-small cell lung cancer, colorectal and breast cancer) (165). For patients with brain tumors cerebrospinal fluid and/or blood contain tumor associated cells, cell free DNA and RNA, and other tumor derived biosources, such as extracellular vesicles (EV) and tumor educated platelets (TEPs). Their analysis will provide a less invasive and hopefully powerful source for early detection, monitoring of disease progression and treatment efficiency in a near future $(122,165,166)$.

Through Papers I-III, we wanted to increase our knowledge about the molecular causes for sex disparity in GBM patients and we looked for potential sex-specific prognostic biomarkers. In Paper I we showed that deletion of the SRY gene and LOY, both detected in the tumor tissue, are associated with shorter survival of males with GBM. The survival advantage of females with GBM was revealed in Paper II, although reported in only one cohort. However, there was a higher frequency of MGMT methylated tumors in females. Paper II and III showed that many sex-specific characteristics of gliomas may go undetected, if sex is not considered as an important factor and included in the analyzes. Both papers showed that reanalysis of established cohorts and clinical trials can remedy this research gap. The main findings from Paper III are the more frequent $A R \mathrm{CN}$ changes in female GBM, increased expression of $A R$ in GBM of both sexes and surprising sex-specific effect of $A R$ gene expression on survival. This also suggests that GBM might have a larger hormone-dependent component, even if to date published reports show inconclusive results.

With increased knowledge of the role of sex differences in glioma, in the future sex specific treatment options might be developed, that will improve survival for both men and women with malignant brain tumors. 


\section{Acknowledgments}

I have been very lucky to meet many kind people that have helped, contributed and sometimes necessarily distracted me on the path to finishing this thesis.

The first person I would like to thank is my main supervisor, Peter Söderkvist. Thank you for seeing the potential in me and inviting me to your research group that became my workfamily over the years. Thank you for the open doors, devoted time that you could always find in your busy schedule, all the learning opportunities and encouragement, all the 'enlightenment hours' and stories about the truly Swedish life. Thank you for allowing me to navigate the world of research many times on my own, which undeniably helped to build my confidence.

Many thanks to Annika Malmström, initially a colleague and $\mathrm{PhD}$ student with whom I got to work and who eventually became my co-supervisor. You are truly inspiring! Thank you for all discussions, clinical and ethical considerations regarding the projects, thank you for always protecting patients' interests. It was a joy to participate in the conferences with you during the day and to drink wine over dinners in the evening. It is your tireless dedication and driving force that makes brain tumor research possible in Linköping.

Thank you to my co-supervisor Olle Stål for the kind words and for the peace of mind that there is always one more person I can ask for help.

Thank you to the collaborators at Linköping University Hospital involved in brain tumor research, Munila Mudaisi, Peter Milos, Martin Hallbeck and others from the South-East Region.

Mouna, Gizeh and Ravi, you were the best office companions over the years! Thank you for the jokes and serious conversations about life, for biryani and couscous cook offs! I hope that palmistry and astrology readings were right, and our lives are full of happiness and professional fulfillment. Thank you for always knowing someone, that knows someone that has the needed equipment or reagent.

None of the lab work could be done without the help from Åsa and Annette- thank you for countless laboratory tips, the assistance of your skillful hands that can make any machine run and thank you for keeping track on all deliveries, even though sometimes it seems to be hopeless. Thanks to you floor 9 felt like home from my very first weeks in the lab.

Thank you to all colleagues from floor 9, past and present, for homemade cakes, fika and lunch discussions, great Christmas parties and help when needed. Thank you for trying to make me speak Swedish- it will work any day now!

To Anita and Awais- thank you for hours and hours of dancing! Thank you for the trips, movie nights and pizza parties. Thank you for being there when I needed it the most! Thank you also to my friends Ali, Mike, Pelle, Connor, João, Teja, Sowjanya, Johannes, Ranjithit was always great fun, and you made my $\mathrm{PhD}$ years very memorable! Basement sessions are THE place to be!

A very special thank you to Pär! In the past couple of years, you were the one person exceptionally grounding me, calming during the peaks of stress and always making sure that 
there was food waiting for me. I cannot imagine being here without you- you are my anchor and happy place on earth.

Największe podziękowania kieruję do mojej rodziny. Mimo dzielących nas kilometrów, zawsze czuję Waszą obecność i wsparcie. To Wy daliście podwaliny moim osiągnięciom dziękuję! 


\section{References}

1. Sung H, Ferlay J, Siegel RL, Laversanne M, Soerjomataram I, Jemal A, et al. Global Cancer Statistics 2020: GLOBOCAN Estimates of Incidence and Mortality Worldwide for 36 Cancers in 185 Countries. CA Cancer J Clin. 2021;71(3):209-49.

2. National Cancer Institute's Surveillance, Epidemiology and End Results program. https://seercancergov/statfacts/html/allhtml.

3. Scala G, Federico A, Palumbo D, Cocozza S, Greco D. DNA sequence context as a marker of CpG methylation instability in normal and cancer tissues. Sci Rep. 2020;10(1):1721.

4. $\mathrm{LiCH}$, Haider S, Boutros PC. Age influences on the molecular presentation of tumours. Nat Commun. 2022;13(1):208.

5. Malkin D, Li FP, Strong LC, Fraumeni JF, Jr., Nelson CE, Kim DH, et al. Germ line p53 mutations in a familial syndrome of breast cancer, sarcomas, and other neoplasms. Science. 1990;250(4985):1233-8.

6. Blackadar CB. Historical review of the causes of cancer. World J Clin Oncol. 2016;7(1):54-86.

7. Ferlay J, Ervik M, Lam F, Colombet M, Mery L, Piñeros M, et al. Global Cancer Observatory: Cancer Today. Lyon: International Agency for Research on Cancer. 2020.

8. Radkiewicz C, Johansson ALV, Dickman PW, Lambe M, Edgren G. Sex differences in cancer risk and survival: A Swedish cohort study. Eur J Cancer. 2017;84:130-40.

9. Ostrom QT, Patil N, Cioffi G, Waite K, Kruchko C, Barnholtz-Sloan JS. CBTRUS Statistical Report: Primary Brain and Other Central Nervous System Tumors Diagnosed in the United States in 2013-2017. Neuro Oncol. 2020;22(12 Suppl 2):iv1-iv96.

10. Ostrom QT, Cioffi G, Waite K, Kruchko C, Barnholtz-Sloan JS. CBTRUS Statistical Report: Primary Brain and Other Central Nervous System Tumors Diagnosed in the United States in 20142018. Neuro Oncol. 2021;23(12 Suppl 2):iii1-iii105.

11. Smith JS, Chang EF, Lamborn KR, Chang SM, Prados MD, Cha S, et al. Role of extent of resection in the long-term outcome of low-grade hemispheric gliomas. J Clin Oncol. 2008;26(8):133845.

12. Molinaro AM, Hervey-Jumper S, Morshed RA, Young J, Han SJ, Chunduru P, et al. Association of Maximal Extent of Resection of Contrast-Enhanced and Non-Contrast-Enhanced Tumor With Survival Within Molecular Subgroups of Patients With Newly Diagnosed Glioblastoma. JAMA Oncol. 2020;6(4):495-503.

13. Wen PY, Weller M, Lee EQ, Alexander BA, Barnholtz-Sloan JS, Barthel FP, et al. Glioblastoma in Adults: A Society for Neuro-Oncology (SNO) and European Society of NeuroOncology (EANO) Consensus Review on Current Management and Future Directions. Neuro Oncol. 2020.

14. Weller M, van den Bent M, Preusser M, Le Rhun E, Tonn JC, Minniti G, et al. EANO guidelines on the diagnosis and treatment of diffuse gliomas of adulthood. Nat Rev Clin Oncol. 2021;18(3):170-86.

15. Yamaoka T, Ohba M, Ohmori T. Molecular-Targeted Therapies for Epidermal Growth Factor Receptor and Its Resistance Mechanisms. Int J Mol Sci. 2017;18(11).

16. Brennan CW, Verhaak RG, McKenna A, Campos B, Noushmehr H, Salama SR, et al. The somatic genomic landscape of glioblastoma. Cell. 2013;155(2):462-77.

17. Wolchok JD, Chiarion-Sileni V, Gonzalez R, Rutkowski P, Grob JJ, Cowey CL, et al. Overall Survival with Combined Nivolumab and Ipilimumab in Advanced Melanoma. N Engl J Med. 2017;377(14):1345-56.

18. Hellmann MD, Paz-Ares L, Bernabe Caro R, Zurawski B, Kim SW, Carcereny Costa E, et al. Nivolumab plus Ipilimumab in Advanced Non-Small-Cell Lung Cancer. N Engl J Med. 2019;381(21):2020-31.

19. Sampson JH, Gunn MD, Fecci PE, Ashley DM. Brain immunology and immunotherapy in brain tumours. Nat Rev Cancer. 2020;20(1):12-25. 
20. Nationell kvalitetsregisterrapport hjärntumörer, 1999-2017. Regionala Cancercentrum i Samverkan. 2018.

21. Molinaro AM, Taylor JW, Wiencke JK, Wrensch MR. Genetic and molecular epidemiology of adult diffuse glioma. Nat Rev Neurol. 2019.

22. Bergqvist J, Iderberg H, Mesterton J, Bengtsson N, Wettermark B, Henriksson R. Healthcare resource use, comorbidity, treatment and clinical outcomes for patients with primary intracranial tumors: a Swedish population-based register study. Acta Oncol. 2017;56(3):405-14. 23. Claus EB, Walsh KM, Wiencke JK, Molinaro AM, Wiemels JL, Schildkraut JM, et al. Survival and low-grade glioma: the emergence of genetic information. Neurosurg Focus. 2015;38(1):E6.

24. Ostrom QT, Adel Fahmideh M, Cote DJ, Muskens IS, Schraw JM, Scheurer ME, et al. Risk factors for childhood and adult primary brain tumors. Neuro Oncol. 2019;21(11):1357-75.

25. Wrensch M, Lee M, Miike R, Newman B, Barger G, Davis R, et al. Familial and personal medical history of cancer and nervous system conditions among adults with glioma and controls. Am J Epidemiol. 1997;145(7):581-93.

26. Bondy ML, Scheurer ME, Malmer B, Barnholtz-Sloan JS, Davis FG, Il'yasova D, et al. Brain tumor epidemiology: consensus from the Brain Tumor Epidemiology Consortium. Cancer. 2008;113(7 Suppl):1953-68.

27. Amirian ES, Zhou R, Wrensch MR, Olson SH, Scheurer ME, Il'yasova D, et al. Approaching a Scientific Consensus on the Association between Allergies and Glioma Risk: A Report from the Glioma International Case-Control Study. Cancer Epidemiol Biomarkers Prev. 2016;25(2):282-90.

28. Kuan AS, Green J, Kitahara CM, Berrington De Gonzalez A, Key T, G KR, et al. Diet and risk of glioma: combined analysis of 3 large prospective studies in the UK and USA. Neuro Oncol. 2019;21(7):944-52.

29. Bagnardi V, Blangiardo M, La Vecchia C, Corrao G. A meta-analysis of alcohol drinking and cancer risk. Br J Cancer. 2001;85(11):1700-5.

30. Cote DJ, Samanic CM, Smith TR, Wang M, Smith-Warner SA, Stampfer MJ, et al. Alcohol intake and risk of glioma: results from three prospective cohort studies. Eur J Epidemiol. 2021;36(9):965-74.

31. Cancer Genome Atlas Research N. Comprehensive genomic characterization defines human glioblastoma genes and core pathways. Nature. 2008;455(7216):1061-8.

32. Cancer Genome Atlas Research N, Brat DJ, Verhaak RG, Aldape KD, Yung WK, Salama SR, et al. Comprehensive, Integrative Genomic Analysis of Diffuse Lower-Grade Gliomas. N Engl J Med. 2015;372(26):2481-98.

33. Hanahan D, Weinberg RA. Hallmarks of cancer: the next generation. Cell. 2011;144(5):646-74.

34. Verhaak RG, Hoadley KA, Purdom E, Wang V, Qi Y, Wilkerson MD, et al. Integrated genomic analysis identifies clinically relevant subtypes of glioblastoma characterized by abnormalities in PDGFRA, IDH1, EGFR, and NF1. Cancer Cell. 2010;17(1):98-110.

35. Capper D, Jones DTW, Sill M, Hovestadt V, Schrimpf D, Sturm D, et al. DNA methylation-based classification of central nervous system tumours. Nature. 2018;555(7697):469-74. 36. Klughammer J, Kiesel B, Roetzer T, Fortelny N, Nemc A, Nenning KH, et al. The DNA methylation landscape of glioblastoma disease progression shows extensive heterogeneity in time and space. Nat Med. 2018;24(10):1611-24.

37. Wenger A, Ferreyra Vega S, Kling T, Bontell TO, Jakola AS, Caren H. Intratumor DNA methylation heterogeneity in glioblastoma: implications for DNA methylation-based classification. Neuro Oncol. 2019;21(5):616-27.

38. Venteicher AS, Tirosh I, Hebert C, Yizhak K, Neftel C, Filbin MG, et al. Decoupling genetics, lineages, and microenvironment in IDH-mutant gliomas by single-cell RNA-seq. Science. 2017;355(6332). 
39. Neftel C, Laffy J, Filbin MG, Hara T, Shore ME, Rahme GJ, et al. An Integrative Model of Cellular States, Plasticity, and Genetics for Glioblastoma. Cell. 2019;178(4):835-49 e21.

40. Louis DN, Ohgaki H, Wiestler OD, Cavenee WK, Burger PC, Jouvet A, et al. The 2007 WHO classification of tumours of the central nervous system. Acta Neuropathol. 2007;114(2):97-109. 41. Louis DN, Perry A, Reifenberger G, von Deimling A, Figarella-Branger D, Cavenee WK, et al. The 2016 World Health Organization Classification of Tumors of the Central Nervous System: a summary. Acta Neuropathol. 2016;131(6):803-20.

42. Han S, Liu Y, Cai SJ, Qian M, Ding J, Larion M, et al. IDH mutation in glioma: molecular mechanisms and potential therapeutic targets. Br J Cancer. 2020;122(11):1580-9.

43. Malta TM, de Souza CF, Sabedot TS, Silva TC, Mosella MS, Kalkanis SN, et al. Glioma CpG island methylator phenotype (G-CIMP): biological and clinical implications. Neuro Oncol. 2018;20(5):608-20.

44. Hegi ME, Diserens AC, Gorlia T, Hamou MF, de Tribolet N, Weller M, et al. MGMT gene silencing and benefit from temozolomide in glioblastoma. N Engl J Med. 2005;352(10):997-1003.

45. Malmstrom A, Gronberg BH, Marosi C, Stupp R, Frappaz D, Schultz H, et al.

Temozolomide versus standard 6-week radiotherapy versus hypofractionated radiotherapy in patients older than 60 years with glioblastoma: the Nordic randomised, phase 3 trial. Lancet Oncol. 2012;13(9):916-26.

46. Mosrati MA, Malmstrom A, Lysiak M, Krysztofiak A, Hallbeck M, Milos P, et al. TERT promoter mutations and polymorphisms as prognostic factors in primary glioblastoma. Oncotarget. 2015;6(18):16663-73.

47. Lombardi G, Giunco S, Cavallin F, Angelini C, Caccese M, Cerretti G, et al. PL02.5.A The clinical significance of telomerase reverse transcriptase (TERT) promoter mutations, telomere length and 06-methylguanine DNA methyltransferase (MGMT) promoter methylation status in newly diagnosed and recurrent IDHwildtype glioblastoma (GBM) patients (PTS): A large mono-institutional study (Abstract). Neuro-Oncology. 2021;23:Pages ii1-ii2.

48. Olympios N, Gilard V, Marguet F, Clatot F, Di Fiore F, Fontanilles M. TERT Promoter Alterations in Glioblastoma: A Systematic Review. Cancers (Basel). 2021;13(5).

49. Lee JH, Lee JE, Kahng JY, Kim SH, Park JS, Yoon SJ, et al. Human glioblastoma arises from subventricular zone cells with low-level driver mutations. Nature. 2018;560(7717):243-7.

50. Muralidharan K, Yekula A, Small JL, Rosh ZS, Kang KM, Wang L, et al. TERT Promoter Mutation Analysis for Blood-Based Diagnosis and Monitoring of Gliomas. Clin Cancer Res. 2021;27(1):169-78.

51. Whitehouse JP, Howlett M, Federico A, Kool M, Endersby R, Gottardo NG. Defining the molecular features of radiation-induced glioma: A systematic review and meta-analysis. Neurooncol Adv. 2021;3(1):vdab109.

52. Stupp R, Mason WP, van den Bent MJ, Weller M, Fisher B, Taphoorn MJ, et al. Radiotherapy plus concomitant and adjuvant temozolomide for glioblastoma. N Engl J Med. 2005;352(10):987-96.

53. Stupp R, Taillibert S, Kanner A, Read W, Steinberg D, Lhermitte B, et al. Effect of Tumor-Treating Fields Plus Maintenance Temozolomide vs Maintenance Temozolomide Alone on Survival in Patients With Glioblastoma: A Randomized Clinical Trial. JAMA. 2017;318(23):2306-16. 54. Rominiyi O, Vanderlinden A, Clenton SJ, Bridgewater C, Al-Tamimi Y, Collis SJ. Tumour treating fields therapy for glioblastoma: current advances and future directions. $\mathrm{Br} \mathrm{J}$ Cancer. 2021;124(4):697-709.

55. Rubin JB, Lagas JS, Broestl L, Sponagel J, Rockwell N, Rhee G, et al. Sex differences in cancer mechanisms. Biol Sex Differ. 2020;11(1):17.

56. Ostrom QT, Rubin JB, Lathia JD, Berens ME, Barnholtz-Sloan JS. Females have the survival advantage in glioblastoma. Neuro Oncol. 2018;20(4):576-7.

57. Tavelin B, Malmström A. Sex Differences in Glioblastoma-Findings from the Swedish National Quality Registry for Primary Brain Tumors between 1999-2018. Journal of Clinical Medicine. $2022 ; 11(3), 486$. 
58. Ostrom QT, Kinnersley B, Wrensch MR, Eckel-Passow JE, Armstrong G, Rice T, et al. Sex-specific glioma genome-wide association study identifies new risk locus at 3p21.31 in females, and finds sex-differences in risk at 8q24.21. Sci Rep. 2018;8(1):7352.

59. Ostrom QT, Coleman W, Huang W, Rubin JB, Lathia JD, Berens ME, et al. Sex-specific gene and pathway modeling of inherited glioma risk. Neuro Oncol. 2019;21(1):71-82.

60. Sun T, Warrington NM, Luo J, Brooks MD, Dahiya S, Snyder SC, et al. Sexually dimorphic RB inactivation underlies mesenchymal glioblastoma prevalence in males. J Clin Invest. 2014;124(9):4123-33.

61. Kfoury N, Sun T, Yu K, Rockwell N, Tinkum KL, Qi Z, et al. Cooperative p16 and p21 action protects female astrocytes from transformation. Acta Neuropathol Commun. 2018;6(1):12. 62. Sherr CJ, McCormick F. The RB and p53 pathways in cancer. Cancer Cell. 2002;2(2):103-12.

63. Haupt S, Caramia F, Herschtal A, Soussi T, Lozano G, Chen H, et al. Identification of cancer sex-disparity in the functional integrity of p53 and its $\mathrm{X}$ chromosome network. Nat Commun. 2019;10(1):5385.

64. Rockwell NC, Yang W, Warrington NM, Staller MV, Griffith M, Griffith OL, et al. Sexand mutation-specific p53 gain-of-function activity in gliomagenesis. Cancer Res Commun. 2021;1(3):148-63.

65. Schiffgens S, Wilkens L, Brandes AA, Meier T, Franceschi E, Ermani M, et al. Sex-specific clinicopathological significance of novel (Frizzled-7) and established (MGMT, IDH1) biomarkers in glioblastoma. Oncotarget. 2016;7(34):55169-80.

66. Zhang H, Liao J, Zhang X, Zhao E, Liang X, Luo S, et al. Sex difference of mutation clonality in diffuse glioma evolution. Neuro Oncol. 2019;21(2):201-13.

67. Yang W, Warrington NM, Taylor SJ, Whitmire P, Carrasco E, Singleton KW, et al. Sex differences in GBM revealed by analysis of patient imaging, transcriptome, and survival data. Sci Transl Med. 2019;11(473).

68. Alvarado AG, Turaga SM, Sathyan P, Mulkearns-Hubert EE, Otvos B, Silver DJ, et al. Coordination of self-renewal in glioblastoma by integration of adhesion and microRNA signaling. Neuro Oncol. 2016;18(5):656-66.

69. Turaga SM, Silver DJ, Bayik D, Paouri E, Peng S, Lauko A, et al. JAM-A functions as a female microglial tumor suppressor in glioblastoma. Neuro Oncol. 2020;22(11):1591-601.

70. Spiers H, Hannon E, Schalkwyk LC, Bray NJ, Mill J. 5-hydroxymethylcytosine is highly dynamic across human fetal brain development. BMC Genomics. 2017;18(1):738.

71. Slieker RC, Roost MS, van Iperen L, Suchiman HE, Tobi EW, Carlotti F, et al. DNA Methylation Landscapes of Human Fetal Development. PLoS Genet. 2015;11(10):e1005583.

72. Xu H, Wang F, Liu Y, Yu Y, Gelernter J, Zhang H. Sex-biased methylome and transcriptome in human prefrontal cortex. Hum Mol Genet. 2014;23(5):1260-70.

73. Bramble MS, Roach L, Lipson A, Vashist N, Eskin A, Ngun T, et al. Sex-Specific Effects of Testosterone on the Sexually Dimorphic Transcriptome and Epigenome of Embryonic Neural Stem/Progenitor Cells. Sci Rep. 2016;6:36916.

74. Nugent BM, Wright CL, Shetty AC, Hodes GE, Lenz KM, Mahurkar A, et al. Brain feminization requires active repression of masculinization via DNA methylation. Nat Neurosci. 2015;18(5):690-7.

75. Johansen ML, Stetson LC, Vadmal V, Waite K, Berens ME, Connor JR, et al. Gliomas display distinct sex-based differential methylation patterns based on molecular subtype. Neurooncol Adv. 2020;2(1):vdaa002.

76. Franceschi E, Tosoni A, Minichillo S, Depenni R, Paccapelo A, Bartolini S, et al. The Prognostic Roles of Gender and 06-Methylguanine-DNA Methyltransferase Methylation Status in Glioblastoma Patients: The Female Power. World Neurosurg. 2018;112:e342-e7.

77. Zylicz JJ, Bousard A, Zumer K, Dossin F, Mohammad E, da Rocha ST, et al. The Implication of Early Chromatin Changes in X Chromosome Inactivation. Cell. 2019;176(1-2):182-97 e23. 
78. Carrel L, Willard HF. X-inactivation profile reveals extensive variability in X-linked gene expression in females. Nature. 2005;434(7031):400-4.

79. Dunford A, Weinstock DM, Savova V, Schumacher SE, Cleary JP, Yoda A, et al. Tumorsuppressor genes that escape from X-inactivation contribute to cancer sex bias. Nat Genet. 2017;49(1):10-6.

80. Kang J, Lee HJ, Kim J, Lee JJ, Maeng LS. Dysregulation of $X$ chromosome inactivation in high grade ovarian serous adenocarcinoma. PLoS One. 2015;10(3):e0118927.

81. Li G, Zhang Z, Jin T, Liang H, Tu Y, Gong L, et al. High frequency of the X-chromosome inactivation in young female patients with high-grade glioma. Diagn Pathol. 2013;8:101.

82. Kfoury N, Qi Z, Prager BC, Wilkinson MN, Broestl L, Berrett KC, et al. Brd4-bound enhancers drive cell-intrinsic sex differences in glioblastoma. Proc Natl Acad Sci U S A. 2021;118(16). 83. Wang GM, Cioffi G, Patil N, Waite KA, Lanese R, Ostrom Q, et al. Importance of the intersection of age and sex to understand variation in incidence and survival for primary malignant gliomas. Neuro Oncol. 2021.

84. Hirtz A, Rech F, Dubois-Pot-Schneider H, Dumond H. Astrocytoma: A HormoneSensitive Tumor? Int J Mol Sci. 2020;21(23).

85. Zhou M, Sareddy GR, Li M, Liu J, Luo Y, Venkata PP, et al. Estrogen receptor beta enhances chemotherapy response of GBM cells by down regulating DNA damage response pathways. Sci Rep. 2019;9(1):6124.

86. Werner CK, Nna UJ, Sun H, Wilder-Romans K, Dresser J, Kothari AU, et al. Expression of the Androgen Receptor Governs Radiation Resistance in a Subset of Glioblastomas Vulnerable to Antiandrogen Therapy. Mol Cancer Ther. 2020;19(10):2163-74.

87. Warburg O. On the origin of cancer cells. Science. 1956;123(3191):309-14.

88. Ray PF, Conaghan J, Winston RM, Handyside AH. Increased number of cells and metabolic activity in male human preimplantation embryos following in vitro fertilization. J Reprod Fertil. 1995;104(1):165-71.

89. Ippolito JE, Yim AK, Luo J, Chinnaiyan P, Rubin JB. Sexual dimorphism in glioma glycolysis underlies sex differences in survival. JCI Insight. 2017;2(15).

90. Sponagel J, Jones JK, Frankfater C, Zhang S, Tung O, Cho K, et al. Sex Differences in Brain Tumor Glutamine Metabolism Reveal Sex-Specific Vulnerabilities to Treatment. bioRxiv preprint. 2021.

91. Hedrington MS, Davis SN. Sexual Dimorphism in Glucose and Lipid Metabolism during Fasting, Hypoglycemia, and Exercise. Front Endocrinol (Lausanne). 2015;6:61.

92. Lombardi G, Rumiato E, Bertorelle R, Saggioro D, Farina P, Della Puppa A, et al. Clinical and Genetic Factors Associated With Severe Hematological Toxicity in Glioblastoma Patients During Radiation Plus Temozolomide Treatment: A Prospective Study. Am J Clin Oncol. 2015;38(5):514-9. 93. Schmetzer O, Florcken A. Sex differences in the drug therapy for oncologic diseases. Handb Exp Pharmacol. 2012(214):411-42.

94. Brahm CG, van Linde ME, Enting RH, Schuur M, Otten RHJ, Heymans MW, et al. The Current Status of Immune Checkpoint Inhibitors in Neuro-Oncology: A Systematic Review. Cancers (Basel). 2020;12(3).

95. Klein SL, Flanagan KL. Sex differences in immune responses. Nat Rev Immunol. 2016;16(10):626-38.

96. Lee J, Kay K, Troike K, Ahluwalia MS, Lathia JD. Sex Differences in Glioblastoma Immunotherapy Response. Neuromolecular Med. 2021.

97. Fyllingen EH, Hansen TI, Jakola AS, Haberg AK, Salvesen O, Solheim O. Does risk of brain cancer increase with intracranial volume? A population-based case control study. Neuro Oncol. 2018;20(9):1225-30.

98. Tschernichovsky R, Katz LH, Derazne E, Berliner MB, Simchoni M, Levine $H$, et al. Height in adolescence as a risk factor for glioma subtypes: a nationwide retrospective cohort study of 2.2 million subjects. Neuro Oncol. 2021;23(8):1383-92. 
99. Bilello M, Akbari H, Da X, Pisapia JM, Mohan S, Wolf RL, et al. Population-based MRI atlases of spatial distribution are specific to patient and tumor characteristics in glioblastoma. Neuroimage Clin. 2016;12:34-40.

100. Li HY, Sun CR, He M, Yin LC, Du HG, Zhang JM. Correlation Between Tumor Location and Clinical Properties of Glioblastomas in Frontal and Temporal Lobes. World Neurosurg. 2018;112:e407-e14.

101. Mackenbach JP, Stirbu I, Roskam AJ, Schaap MM, Menvielle G, Leinsalu M, et al. Socioeconomic inequalities in health in 22 European countries. N Engl J Med. 2008;358(23):2468-81. 102. Carstam L, Ryden I, Gulati S, Rydenhag B, Henriksson R, Salvesen O, et al. Socioeconomic factors affect treatment delivery for patients with low grade glioma: a Swedish population-based study. J Neurooncol. 2020;146(2):329-37.

103. Stabellini N, Krebs H, Patil N, Waite K, Barnholtz-Sloan JS. Sex Differences in Time to Treat and Outcomes for Gliomas. Front Oncol. 2021;11:630597.

104. Forst D, Adams E, Nipp R, Martin A, El-Jawahri A, Aizer A, et al. Hospice utilization in patients with malignant gliomas. Neuro Oncol. 2018;20(4):538-45.

105. Erdem-Eraslan L, Gravendeel LA, de Rooi J, Eilers PH, Idbaih A, Spliet WG, et al. Intrinsic molecular subtypes of glioma are prognostic and predict benefit from adjuvant procarbazine, lomustine, and vincristine chemotherapy in combination with other prognostic factors in anaplastic oligodendroglial brain tumors: a report from EORTC study 26951. J Clin Oncol. 2013;31(3):328-36.

106. Cairncross JG, Wang M, Jenkins RB, Shaw EG, Giannini C, Brachman DG, et al. Benefit from procarbazine, lomustine, and vincristine in oligodendroglial tumors is associated with mutation of IDH. J Clin Oncol. 2014;32(8):783-90.

107. Poon MTC, Sudlow CLM, Figueroa JD, Brennan PM. Longer-term ( $>/=2$ years) survival in patients with glioblastoma in population-based studies pre- and post-2005: a systematic review and meta-analysis. Sci Rep. 2020;10(1):11622.

108. Weller M, Reifenberger G, Le Rhun E, Clarke JL, Soffietti R, Wick W, et al. Molecular genetic, host-derived and clinical determinants of long-term survival in glioblastoma: First results from the ETERNITY study (EORTC 1419). J Clin Oncol. 2019; Volume 37(Issue 15_suppl).

109. Marton E, Giordan E, Siddi F, Curzi C, Canova G, Scarpa B, et al. Over ten years overall survival in glioblastoma: A different disease? J Neurol Sci. 2020;408:116518.

110. Adeberg S, Bostel T, Konig L, Welzel T, Debus J, Combs SE. A comparison of long-term survivors and short-term survivors with glioblastoma, subventricular zone involvement: a predictive factor for survival? Radiat Oncol. 2014;9:95.

111. Bozdag S, Li A, Riddick G, Kotliarov Y, Baysan M, Iwamoto FM, et al. Age-specific signatures of glioblastoma at the genomic, genetic, and epigenetic levels. PLoS One. 2013;8(4):e62982.

112. Schumacher B, Pothof J, Vijg J, Hoeijmakers JHJ. The central role of DNA damage in the ageing process. Nature. 2021;592(7856):695-703.

113. Hwang T, Mathios D, McDonald KL, Daris I, Park SH, Burger PC, et al. Integrative analysis of DNA methylation suggests down-regulation of oncogenic pathways and reduced somatic mutation rates in survival outliers of glioblastoma. Acta Neuropathol Commun. 2019;7(1):88.

114. Ma J, Hou X, Li M, Ren H, Fang S, Wang X, et al. Genome-wide methylation profiling reveals new biomarkers for prognosis prediction of glioblastoma. J Cancer Res Ther. 2015;11 Suppl 2:C212-5.

115. Shinawi T, Hill VK, Krex D, Schackert G, Gentle D, Morris MR, et al. DNA methylation profiles of long- and short-term glioblastoma survivors. Epigenetics. 2013;8(2):149-56.

116. Berendsen S, Varkila M, Kroonen J, Seute T, Snijders TJ, Kauw F, et al. Prognostic relevance of epilepsy at presentation in glioblastoma patients. Neuro Oncol. 2016;18(5):700-6.

117. Sykes PJ, Neoh SH, Brisco MJ, Hughes E, Condon J, Morley AA. Quantitation of targets for PCR by use of limiting dilution. Biotechniques. 1992;13(3):444-9. 
118. Pinheiro LB, Coleman VA, Hindson CM, Herrmann J, Hindson BJ, Bhat S, et al.

Evaluation of a droplet digital polymerase chain reaction format for DNA copy number quantification. Anal Chem. 2012;84(2):1003-11.

119. Miotke L, Lau BT, Rumma RT, Ji HP. High sensitivity detection and quantitation of DNA copy number and single nucleotide variants with single color droplet digital PCR. Anal Chem. 2014;86(5):2618-24.

120. Hindson BJ, Ness KD, Masquelier DA, Belgrader P, Heredia NJ, Makarewicz AJ, et al. High-throughput droplet digital PCR system for absolute quantitation of DNA copy number. Anal Chem. 2011;83(22):8604-10.

121. Malmstrom A, Poulsen HS, Gronberg BH, Stragliotto G, Hansen S, Asklund T, et al. Postoperative neoadjuvant temozolomide before radiotherapy versus standard radiotherapy in patients 60 years or younger with anaplastic astrocytoma or glioblastoma: a randomized trial. Acta Oncol. 2017;56(12):1776-85.

122. Soffietti R, Bettegowda C, Mellinghoff IK, Warren KE, Ahluwalia MS, De Groot JF, et al. Liquid biopsy in gliomas: a RANO review and proposals for clinical applications. Neuro Oncol. 2022.

123. Wick W, Platten M, Meisner C, Felsberg J, Tabatabai G, Simon M, et al. Temozolomide chemotherapy alone versus radiotherapy alone for malignant astrocytoma in the elderly: the NOA-08 randomised, phase 3 trial. Lancet Oncol. 2012;13(7):707-15.

124. Gitan RS, Shi H, Chen CM, Yan PS, Huang TH. Methylation-specific oligonucleotide microarray: a new potential for high-throughput methylation analysis. Genome Res. 2002;12(1):15864.

125. Mazumdar M, Glassman JR. Categorizing a prognostic variable: review of methods, code for easy implementation and applications to decision-making about cancer treatments. Stat Med. 2000;19(1):113-32.

126. Malmstrom A, Lysiak M, Kristensen BW, Hovey E, Henriksson R, Soderkvist P. Do we really know who has an MGMT methylated glioma? Results of an international survey regarding use of MGMT analyses for glioma. Neurooncol Pract. 2020;7(1):68-76.

127. Hothorn T, Lausen B. Maximally Selected Rank Statistics in R. 2002.

128. Lausen B, Schumacher M. Maximally selected rank statistics. Biometrics. 1992;48:73-

85.

129. Malmstrom A, Lysiak M, Akesson L, Jakobsen I, Mudaisi M, Milos P, et al. ABCB1 singlenucleotide variants and survival in patients with glioblastoma treated with radiotherapy concomitant with temozolomide. Pharmacogenomics J. 2020;20(2):213-9.

130. Bowman RL, Wang Q, Carro A, Verhaak RG, Squatrito M. GlioVis data portal for visualization and analysis of brain tumor expression datasets. Neuro Oncol. 2017;19(1):139-41.

131. GlioVis Data Visualization Tools for Brain Tumor Datasets. GlioVis Explore 2020, January 15 [Available from: http://gliovis.bioinfo.cnio.es/.

132. Forsberg LA, Rasi C, Malmqvist N, Davies H, Pasupulati S, Pakalapati G, et al. Mosaic loss of chromosome $Y$ in peripheral blood is associated with shorter survival and higher risk of cancer. Nat Genet. 2014;46(6):624-8.

133. Hollows R, Wei W, Cazier JB, Mehanna H, Parry G, Halford G, et al. Association between loss of $Y$ chromosome and poor prognosis in male head and neck squamous cell carcinoma. Head Neck. 2019;41(4):993-1006.

134. Machiela MJ, Dagnall CL, Pathak A, Loud JT, Chanock SJ, Greene MH, et al. Mosaic chromosome $Y$ loss and testicular germ cell tumor risk. J Hum Genet. 2017;62(6):637-40.

135. Caceres A, Jene A, Esko T, Perez-Jurado LA, Gonzalez JR. Extreme down-regulation of chromosome $Y$ and cancer risk in men. J Natl Cancer Inst. 2020.

136. Wright DJ, Day FR, Kerrison ND, Zink F, Cardona A, Sulem P, et al. Genetic variants associated with mosaic $\mathrm{Y}$ chromosome loss highlight cell cycle genes and overlap with cancer susceptibility. Nat Genet. 2017;49(5):674-9.

137. Thompson DJ, Genovese G, Halvardson J, Ulirsch JC, Wright DJ, Terao C, et al. Genetic predisposition to mosaic Y chromosome loss in blood. Nature. 2019;575(7784):652-7. 
138. Zalcman N, Canello T, Ovadia H, Charbit H, Zelikovitch B, Mordechai A, et al. Androgen receptor: a potential therapeutic target for glioblastoma. Oncotarget. 2018;9(28):19980-93.

139. Zhao N, Wang F, Ahmed S, Liu K, Zhang C, Cathcart SJ, et al. Androgen Receptor, Although Not a Specific Marker For, Is a Novel Target to Suppress Glioma Stem Cells as a Therapeutic Strategy for Glioblastoma. Front Oncol. 2021;11:616625.

140. Bao D, Cheng C, Lan X, Xing R, Chen Z, Zhao H, et al. Regulation of p53wt glioma cell proliferation by androgen receptor-mediated inhibition of small VCP/p97-interacting protein expression. Oncotarget. 2017;8(14):23142-54.

141. Wang Q, Hu B, Hu X, Kim H, Squatrito M, Scarpace L, et al. Tumor Evolution of GliomaIntrinsic Gene Expression Subtypes Associates with Immunological Changes in the Microenvironment. Cancer Cell. 2017;32(1):42-56 e6.

142. Hu C, Fang $\mathrm{D}, \mathrm{Xu} \mathrm{H}$, Wang $\mathrm{Q}$, Xia $\mathrm{H}$. The androgen receptor expression and association with patient's survival in different cancers. Genomics. 2020;112(2):1926-40.

143. Bolla M, Van Tienhoven G, Warde P, Dubois JB, Mirimanoff RO, Storme G, et al. External irradiation with or without long-term androgen suppression for prostate cancer with high metastatic risk: 10-year results of an EORTC randomised study. Lancet Oncol. 2010;11(11):1066-73. 144. Speers C, Zhao SG, Chandler B, Liu M, Wilder-Romans K, Olsen E, et al. Androgen receptor as a mediator and biomarker of radioresistance in triple-negative breast cancer. NPJ Breast Cancer. 2017;3:29.

145. Chamberlain NL, Driver ED, Miesfeld RL. The length and location of CAG trinucleotide repeats in the androgen receptor $\mathrm{N}$-terminal domain affect transactivation function. Nucleic Acids Res. 1994;22(15):3181-6.

146. Andersson $P$, Varenhorst E, Soderkvist P. Androgen receptor and vitamin D receptor gene polymorphisms and prostate cancer risk. Eur J Cancer. 2006;42(16):2833-7.

147. Lee Y, Lee JK, Ahn SH, Lee J, Nam DH. WNT signaling in glioblastoma and therapeutic opportunities. Lab Invest. 2016;96(2):137-50.

148. Chai RC, Chang YZ, Wang QW, Zhang KN, Li JJ, Huang H, et al. A Novel DNA Methylation-Based Signature Can Predict the Responses of MGMT Promoter Unmethylated Glioblastomas to Temozolomide. Front Genet. 2019;10:910.

149. Feng Y, Li G, Shi Z, Yan X, Wang Z, Jiang H, et al. A novel methylation signature predicts radiotherapy sensitivity in glioma. Sci Rep. 2020;10(1):20406.

150. Horvath S. DNA methylation age of human tissues and cell types. Genome Biol. 2013;14(10):R115.

151. Hannum G, Guinney J, Zhao L, Zhang L, Hughes G, Sadda S, et al. Genome-wide methylation profiles reveal quantitative views of human aging rates. Mol Cell. 2013;49(2):359-67. 152. Levine ME, Lu AT, Quach A, Chen BH, Assimes TL, Bandinelli S, et al. An epigenetic biomarker of aging for lifespan and healthspan. Aging (Albany NY). 2018;10(4):573-91.

153. Zheng C, Berger NA, Li L, Xu R. Epigenetic age acceleration and clinical outcomes in gliomas. PLoS One. 2020;15(7):e0236045.

154. Liao P, Ostrom QT, Stetson L, Barnholtz-Sloan JS. Models of epigenetic age capture patterns of DNA methylation in glioma associated with molecular subtype, survival, and recurrence. Neuro Oncol. 2018;20(7):942-53.

155. Chaligne R, Gaiti F, Silverbush D, Schiffman JS, Weisman HR, Kluegel L, et al. Epigenetic encoding, heritability and plasticity of glioma transcriptional cell states. Nat Genet.

2021;53(10):1469-79.

156. Capper D, Stichel D, Sahm F, Jones DTW, Schrimpf D, Sill M, et al. Practical implementation of DNA methylation and copy-number-based CNS tumor diagnostics: the Heidelberg experience. Acta Neuropathol. 2018;136(2):181-210.

157. Mellinghoff IK, Ellingson BM, Touat M, Maher E, De La Fuente MI, Holdhoff M, et al. Ivosidenib in Isocitrate Dehydrogenase 1-Mutated Advanced Glioma. J Clin Oncol. 2020;38(29):3398406. 
158. Platten M, Bunse L, Wick A, Bunse T, Le Cornet L, Harting I, et al. A vaccine targeting mutant IDH1 in newly diagnosed glioma. Nature. 2021;592(7854):463-8.

159. Tesileanu CMS, van den Bent MJ, Sanson M, Wick W, Brandes AA, Clement PM, et al. Prognostic significance of genome-wide DNA methylation profiles within the randomized, phase 3 , EORTC CATNON trial on non-1p/19q deleted anaplastic glioma. Neuro Oncol. 2021;23(9):1547-59.

160. Kuschel LP, Hench J, Frank S, Hench IB, Girard E, Blanluet M, et al. Robust methylationbased classification of brain tumors using nanopore sequencing. medRxiv.

2021:2021.03.06.21252627.

161. Euskirchen P, Bielle F, Labreche K, Kloosterman WP, Rosenberg S, Daniau M, et al. Same-day genomic and epigenomic diagnosis of brain tumors using real-time nanopore sequencing. Acta Neuropathol. 2017;134(5):691-703.

162. Kono N, Arakawa K. Nanopore sequencing: Review of potential applications in functional genomics. Dev Growth Differ. 2019;61(5):316-26.

163. Doz F, van Tilburg CM, Geoerger B, Hojgaard M, Ora I, Boni V, et al. Efficacy and safety of larotrectinib in TRK fusion-positive primary central nervous system tumors. Neuro Oncol. 2021.

164. You G, Fan X, Hu H, Jiang T, Chen CC. Fusion Genes Altered in Adult Malignant Gliomas. Front Neurol. 2021;12:715206.

165. Best MG, Sol N, Kooi I, Tannous J, Westerman BA, Rustenburg F, et al. RNA-Seq of Tumor-Educated Platelets Enables Blood-Based Pan-Cancer, Multiclass, and Molecular Pathway Cancer Diagnostics. Cancer Cell. 2015;28(5):666-76.

166. Sol N, In 't Veld S, Vancura A, Tjerkstra M, Leurs C, Rustenburg F, et al. TumorEducated Platelet RNA for the Detection and (Pseudo)progression Monitoring of Glioblastoma. Cell Rep Med. 2020;1(7):100101. 
Appendix (Paper I-IV) 


\section{Papers}

The papers associated with this thesis have been removed for copyright reasons. For more details about these see:

https://doi.org/10.3384/9789179291556 



\section{FACULTY OF MEDICINE AND HEALTH SCIENCES}

Linköping University Medical Dissertation No. 1796, 2022

Department of Biomedical and Clinical Sciences

Linköping University

SE-58183 Linköping, Sweden

www.liu.se 